\title{
Ambulacrarian insulin-related peptides and their putative receptors suggest how insulin and similar peptides may have evolved from Insulin-like Growth Factor
}

\author{
Jan A Veenstra ${ }^{\text {Corresp. } 1}$ \\ 1 INCIA UMR 5287 CNRS, Université de Bordeaux, Pessac, Gironde, FRANCE \\ Corresponding Author: Jan A Veenstra \\ Email address: jan-adrianus.veenstra@u-bordeaux.fr
}

\section{Background}

Some Insulin/IGF-related peptides (irps) stimulate a receptor tyrosine kinase (RTK) that transfers the extracellular hormonal signal into an intracellular response. Other irps, such as relaxin, do not use an RTK, but a G-protein coupled receptor (GPCR). This is unusual since evolutionarily related hormones typically either use the same or paralogous receptors. In arthropods three different irps, i.e. arthropod IGF, gonadulin and Drosophila insulin-like peptide 7 (dilp7), likely evolved from a gene triplication, as in several species genes encoding these three peptides are located next to one another on the same chromosomal fragment. These arthropod irps have homologs in vertebrates, suggesting that the initial gene triplication was perhaps already present in the last common ancestor of deuterostomes and protostomes. It would be interesting to know whether this is indeed so and how insulin might be related to this trio of irps.

\section{Methodology}

Genes encoding irps as well as their putative receptors were identified in genomes and transcriptomes from echinoderms and hemichordates.

\section{Results}

A similar triplet of genes coding for irps also occurs in some ambulacrarians. Two of these are orthologs of arthropod IGF and dilp7 and the third is likely a gonadulin ortholog. In echinoderms, two novel irps emerged, gonad stimulating substance (GSS) and multinsulin, likely from gene duplications of the IGF and dilp7-like genes respectively. The structures of GSS diverged considerably from IGF, which would suggest they use different receptors from IGF, but no novel irp receptors evolved. If IGF and GSS use different receptors, and the evolution of GSS from a gene duplication of IGF is not associated with the appearance of a novel receptor, while irps are known to use two different types of receptors, the ancestor of GSS and IGF might have acted on both types of receptors while one or both of its descendants act on only one. There are three ambulacrarian GPCRs that have amino acid sequences suggestive of being irp GPCRs, two of these are orthologs of the gonadulin and dilp7 receptors. This suggests that the third might be an IGF receptor, and that by deduction, GSS only acts on the RTK. The evolution of GSS from IGF may represent a pattern, where IGF gene duplications lead to novel genes coding for shorter peptides that activate an RTK. It is likely this is how insulin and the insect neuroendocrine irps evolved independently from IGF. 
The local gene triplication described from arthropods that yielded three genes encoding irps was already present in the last common ancestor of protostomes and deuterostomes. It seems plausible that irps, such as those produced by neuroendocrine cells in the brain of insects and echinoderm GSS evolved independently from IGF and, thus, are not true orthologs, but the result of convergent evolution. 
1 Ambulacrarian insulin-related peptides and their

2 putative receptors suggest how insulin and similar

3 peptides may have evolved from Insulin-like Growth

4 Factor

5

6 Jan A. Veenstra ${ }^{1}$,

7

$8{ }^{1}$ INCIA UMR 5287 CNRS, Université de Bordeaux, Pessac, France.

10 Corresponding Author:

11 Jan A. Veenstra ${ }^{1}$

12 INCIA UMR 5287 CNRS, Université de Bordeaux, allée Geoffroy St Hillaire, CS 50023, 33615

13 Pessac Cedex, France 
14 Email address: jan-adrianus.veenstra@,u-bordeaux.fr

\section{Abstract}

\section{Background}

24 Some Insulin/IGF-related peptides (irps) stimulate a receptor tyrosine kinase (RTK) that

25 transfers the extracellular hormonal signal into an intracellular response. Other irps, such as 26 relaxin, do not use an RTK, but a G-protein coupled receptor (GPCR). This is unusual since

27 evolutionarily related hormones typically either use the same or paralogous receptors. In

28 arthropods three different irps, i.e. arthropod IGF, gonadulin and Drosophila insulin-like peptide

297 (dilp7), likely evolved from a gene triplication, as in several species genes encoding these three

30 peptides are located next to one another on the same chromosomal fragment. These arthropod

31 irps have homologs in vertebrates, suggesting that the initial gene triplication was perhaps

32 already present in the last common ancestor of deuterostomes and protostomes. It would be

33 interesting to know whether this is indeed so and how insulin might be related to this trio of irps.

\section{Methodology}

35 Genes encoding irps as well as their putative receptors were identified in genomes and

36 transcriptomes from echinoderms and hemichordates. 


\section{Results}

38 A similar triplet of genes coding for irps also occurs in some ambulacrarians. Two of these are orthologs of arthropod IGF and dilp7 and the third is likely a gonadulin ortholog. In echinoderms

40 two novel irps emerged, gonad stimulating substance (GSS) and multinsulin, likely from gene

41 duplications of the IGF and dilp7-like genes respectively. The structures of GSS diverged

42 considerably from IGF, which would suggest they use different receptors from IGF, but no novel

43 irp receptors evolved. If IGF and GSS use different receptors, and the evolution of GSS from a

44 gene duplication of IGF is not associated with the appearance of a novel receptor, while irps are 45 known to use two different types of receptors, the ancestor of GSS and IGF might have acted on

46 both types of receptors while one or both of its descendants act on only one. There are three

47 ambulacrarian GPCRs that have amino acid sequences suggestive of being irp GPCRs, two of

48 these are orthologs of the gonadulin and dilp7 receptors. This suggests that the third might be an IGF receptor, and that by deduction, GSS only acts on the RTK. The evolution of GSS from IGF may represent a pattern, where IGF gene duplications lead to novel genes coding for shorter peptides that activate an RTK. It is likely this is how insulin and the insect neuroendocrine irps evolved independently from IGF.

\section{Conclusion}

The local gene triplication described from arthropods that yielded three genes encoding irps was already present in the last common ancestor of protostomes and deuterostomes. It seems plausible that irps, such as those produced by neuroendocrine cells in the brain of insects and echinoderm GSS evolved independently from IGF and, thus, are not true orthologs, but the result 58 of convergent evolution.

61 Key words: insulin; relaxin; receptor tyrosine kinase; G-protein coupled receptor; evolution; gonadulin; octinsulin; multinsulin; dilp7 


\section{Introduction}

64

65

66

67

68

69

70

71

72

73

74

75

76

77

78

79

80

81

82

83

84

85

86

87

88

89

90

91

92

93

Many protein hormone and neuropeptide signaling pathways have orthologs in both protostomes and deutertostomes showing that these pathways were already present in their last common bilaterian ancestor. In some cases, the orthologs of the peptide ligands show only limited sequence similarity, but their receptors contain protein domains that are sufficiently conserved to establish homology. Virtually all ligands employ either a single receptor or a number of related receptors that evolved by gene duplication. Co-evolution of peptide ligands and receptors insures that related protein hormones or neuropeptides use receptors akin to those of their orthologs (Mirabeau \& Joly, 2013; Hsueh \& Feng, 2020).

Insulin/IGF-related peptides (irps) are an exception to this rule. Whereas insulin and IGF act through a receptor tyrosine kinase (RTK), relaxin uses a leucine-rich repeat G-protein coupled receptor (LGR). This raises the interesting question as how this apparent jump from one type of receptor to another may have come about. In cockroaches, termites and stick insects three different irp genes (i.e. gonadulin, arthropod insulin-like growth factor (aIGF) and arthropod relaxin) are located next to one another in the genome and thus likely originated from a local gene triplication (Veenstra, 2020b). To avoid confusion with the vertebrate relaxins and related peptides, the arthropod relaxins will be referred to as Drosophila ilp7 (dilp7) in this manuscript. One of the irps, aIGF, is known to use an insulin RTK, while gonadulin acts through insect LGR3 (Vallejo et al., 2015; Garelli et al., 2015; Colombani et al., 2015). Bioinformatic evidence suggested that dilp7 must be the ligand for insect LGR4, and this has now been confirmed experimentally in Drosophila (Veenstra, Rombauts \& Grbić, 2012; Imambocus et al., 2020), but dilp7 may also activate an RTK (Linneweber et al., 2014). This suggests that the archtype arthropod IGF-related peptide acted through both an RTK and an LGR and that after a likely gene triplication, some of the ligands may have lost one of the two original receptors. Although it is possible that the gene triplication of the ancestral insulin gene occurred in an early arthropod or protostomian, it may well have occurred in a bilaterian ancestor, as homologs of both aIGF and dilp7 are also present in deuterostomes.

Brain neuroendocrine insect irps are more closely related to IGF than either dilp7 or gonadulin. Therefore, a gene duplication that gave rise to separate genes encoding these peptides is likely to have occurred after the triplication that gave rise to the ancestor genes of gonadulin and dilp7. Yet in insect genomes irp genes are not located near the IGF gene. Thus, the particular 
94 organization of these genes suggests that whereas the gonadulin and dilp7 genes likely originated

95 by two successive local gene duplications, the IGF gene duplication that gave rise to an initial

96 arthropod neuroendocrine brain irp must have materialized in a different fashion. If the earlier

97 mentioned gene triplication was already present in the last common ancestor of the

98 deuterostomes then a similar argument can also be made for the evolution of insulin. Given the

99 importance of insulin as a human hormone and the inherent interest of its evolutionary origin, I

100 explored the evolution of bilaterian insulin-related peptides in more detail and here report on the

101 genes coding for such peptides and their receptors in the Ambulacraria that suggest how insulin

102 may have evolved from IGF.

103

\section{Materials and Methods}

\section{Nomenclature}

106 Hormones have often been discovered independently by different groups using different

107 bioassays. The vertebrate insulin-like growth factors are a good example of that. Predicted

108 protostomian peptides and their receptors have sometimes been given names that refer to similar

109 deuterostomian proteins. In some cases this is very confusing, e.g. vertebrate LGR-3, -4 and -5

110 are not the orthologs of arthropod receptors that have been given the same names. A similar

111 problem occurs with arthropod relaxin that is not an ortholog of vertebrate relaxin. This peptide

112 will therefore be called dilp7 (Drosophila insulin-like peptide 7). I will refer to arthropod LGR3

113 as the gonadulin receptor, arthropod LGR4 as the dilp7 receptor and arthropod LGR5 as

114 GRL101, a GPCR initially identified from the pond snail Lymnaea stagnalis (Tensen et al.,

115 1994) that is an ortholog of arthropod LGR5 (Veenstra, 2020b).

116 Another nomenclature problem concerns the terms, insulin-like and insulin-related that are

117 not well defined. Insulin and IGF are related and must share a common evolutionary origin with

118 other peptide ligands like vertebrate relaxin, INSL3, arthropod dilp7 and gonadulin and a large

119 number of other bilaterian peptides. All these peptides are often collectively called insulin-like or

120 insulin-related without any specification as to in which aspects these hormones are similar to

121 insulin. The typical core sequence of six cysteine residues and its use of an RTK are two

122 characters that are shared by vertebrate IGF and insulin. However, several related peptides have

123 eight cysteine residues and others like vertebrate relaxin use an LGR and not an RTK. Insulin

124 and IGF are also different in that IGF is a single chain molecule, while the insulin precursor is 
125 processed into a two chain molecule. The term insulin-like seems more appropriate for a subset

126 of the insulin/IGF-related peptides that look similar to insulin and act through an RTK, yet are

127 different from IGF. Calling IGF-related peptides, like vertebrate relaxin, INSL3 or arthropod

128 gonadulin for which there is no evidence that they act through an RTK, insulin-like is confusing.

129 Unfortunately for many bilaterian peptides we can only speculate as to which type of receptor

130 they use. The difference between one or two chain ligands, i.e. IGF versus insulin, is also useless

131 as there is good evidence that some insect IGF-related peptides are processed into two-chain

132 molecules when expressed in neuroendocrine cells and produced as single chain ligands when

133 produced by the fat body, yet in both cases stimulate an RTK. It is for these reasons that all these

134 peptides will be referred to as insulin/IGF-related peptides, abbreviated irps.

136 Sequence analysis

137 Sequences for insulin related peptides and their likely receptors were identified from a 138 number of Ambulacraria species. This was done using the Artemis program (Rutherford et al., 139 2000) and the BLAST+ program (ftp://ftp.ncbi.nlm.nih.gov/blast/executables/blast+/) on

140 publicly available genome sequences from the feather star Anneissia japonica, the sea urchins

141 Lytechinus variegatus (Davidson et al., 2000) and Strongylocentrus purpuratus (Sea Urchin

142 Genome Sequencing Consortium, 2006), the sea cucumbers Apostichopus japonicus (Jo et al.,

143 2017; Zhang et al., 2017) and Holothuria glaberrima, the sea stars Acanthaster planci (Hall et

144 al., 2017), Pisaster ochraceus (Ruiz-Ramos et al., 2020) and Patiria miniata, the brittle star

145 Ophiothrix spiculata and the hemichordates Saccoglossus kowalevskii and Ptychodera flava

146 (Simakov et al., 2015). The genomes were downloaded from

147 https://www.ncbi.nlm.nih.gov/genome. For many of these species there are also significant

148 amounts of RNAseq data. These were analyzed using the sratoolkit

149 (https://trace.ncbi.nlm.nih.gov/Traces/sra/sra.cgi?view=software ) in combination with Trinity

150 (Grabherr et al., 2011) by methods described in detail elsewhere (Veenstra, 2020b). Some

151 protein sequences were found in the NCBI database, but several of them contain errors or are

152 incomplete. Where possible these were corrected and/or completed using the methods described

153 above. As there is only a single crinoid genome assembly available, transcriptome data from the

154 three crinoid species Antedon mediterranea, Florometra serratissima and Oligometra serripinna

155 were also included. For the same reason transcriptome data from the brittle star Amphiura

PeerJ reviewing PDF | (2021:04:60199:2:0:REVIEW 22 Jun 2021) 
156 filiformis, Ophioderma brevispina and the hemichordate Schizocardium californicum were

157 likewise analyzed. Obviously, transcriptome data can only demonstrate the presence of gene but

158 not its absence, and their usefulness depends largely on the variety of tissues sampled and the

159 expression levels of the genes of interest. Nevertheless, such data often provide additional

160 sequences that, even if they are incomplete, increase the robustness of sequence comparisons.

161 Genomic and transcriptomic RNAseq short read archives (SRAs) were downloaded from NCBI

162 (https://www.ncbi.nlm.nih.gov/sra/); a list of the SRAs analyzed is provided in the

163 supplementary data.

164 As queries for the insulin-like peptides, a number of such peptides from a variety of species

165 were used. Insulin RTKs are easily identified in genome and transcriptome assemblies, as their

166 kinase domains are very well conserved. The LGRs that could function as insulin receptors are

167 more variable. Vertebrate LGRs RXFP1 and RXFP2are known receptors for relaxin and Ins3 and

168 Drosophila LGR3 and LGR4 for gonadulin, and dilp7 respectively. Other LGRs function as

169 receptors for the various glycoprotein hormones, GPA2/GPB5, bursicon, TSH, FSH and LH.

170 These GPCRs cluster on phylogenetic trees with another protostomian LGR, GRL101. This

171 GPCR was initially identified from the pond snail Lymnaea stagnalis and was the first GPCR

172 discovered to have, in addition to six leucine-rich repeats, twelve repeats of a sequence that was

173 known to exist in the low density lipoprotein receptor and are now called LDLa repeats (Tensen

174 et al., 1994). I have suggested previously (Veenstra, 2020b) that this receptor might be an IGF

175 receptor.

176 Both the RTK and LGR receptors have large ectodomains. Those of the insulin RTKs are

177 very similar from one receptor to another, while those of the LGRs differ between different

178 types. The latter all contain numerous Leucine-rich repeats (LRRs), and some also have LDL-

179 receptor class A (LDLa) repeats. Both LRRs and LDLa's are present in many other proteins.

180 Initial searches for orthologous receptors were, therefore, done using the transmembrane regions

181 of various insect and vertebrate LGRs and the protein kinase domain of RTK. Once partial

182 sequences of putative receptors were identified, the coding sequences of these domains were then

183 used to complete the cDNA sequences as best as possible, using either Trinity on RNAseq SRAs

184 or Artemis on genome sequences.

185

186

Sequence similarity and phylogenetic trees

Peer) reviewing PDF | (2021:04:60199:2:0:REVIEW 22 Jun 2021) 
Both phylogenetic and sequence similarity trees use Clustal omega (Sievers et al., 2011) to produce alignments. Fasttree (Price, Dehal \& Arkin, 2010), using the ./FastTreeDbl command with the -spr 4, -mlacc 2 and -slownni options, was used to construct trees and estimate probabilities.

In order to identify putative receptors for the various irps, LGRs that show homology to various arthropod and vertebrate LGRs were identified and a phylogenetic tree based exclusively on the transmembrane regions of these receptors was constructed.

\section{Precursor processing}

196 Precursors of insulin-like peptides contain signal peptides that are removed on entry into the endoplasmatic reticulum. Signal P 5.0 (Almagro Armenteros et al., 2019) was used online (http://www.cbs.dtu.dk/services/SignalP/) to predict where this cleavage would most likely occur. Some, but not all precursors are further processed by convertases. Of these furin is ubiquitously present in all cell types and can thus potentially cleave any secreted protein with an appropriate cleavage site. Its consensus cleavage site is $\mathrm{K} / \mathrm{R}-\mathrm{X}-\mathrm{K} / \mathrm{R}-\mathrm{R}$; the two human IGF precursors are processed at KSAR and KSER, respectively (Humbel, 1990). Precursors that are produced in cells with a regulated pathway, such as neuroendocrine and enteroendocrine cells, are also exposed to other convertases like PC1/3 and PC2. Their consensus cleavages site is KR. However, effective proteolytic processing by convertases is strongly influenced by amino acid residues surrounding these consensus cleavage sites. For example, bulky residues immediately following the arginine residue, a proline residue before the consensus site, or disulfide bridges nearby can cause sufficient steric hindrance to inhibit cleavage. Using rules proposed to predict cleavage by PC1/3 and PC2 in both vertebrates and insects (Devi, 1991; Rholam et al., 1995; Veenstra, 2000), I have tried to indicate where the various precursors might be cleaved. It must

211 be noted, however, that there is no certainty that these sites will be cleaved, nor can it be

212 excluded that proteolytic processing occurs at sites that have not been indicated as such.

\section{Expression}

215 With a few notable exceptions (e.g. Lin et al., 2017), little is known about the expression of 216 the various insulin-like peptides in either echinoderms or hemichordates. Except for the GSS our

217 knowledge of their functions is also very limited. Expression data may reveal some preliminary 
218 clues as to where and when they are expressed and thus provide a hint as to their function. For

219 this reason the number of reads corresponding to the various insulin-related peptides and their

220 putative receptors was determined in a number of SRAs to provide evidence as to the time and

221 tissue specific expression of these proteins. The analysis was performed as described previously

222 (Veenstra, 2020b), and the data are supplied in Spreadsheet S2.

223

224

\section{Results}

226

\section{Peptides related to insulin and IGF}

Some protein sequences were found in the NCBI database, but several of them contain errors or are incomplete. Where possible, these were corrected and/or completed using the methods described above. As there is only a single crinoid genome assembly available, transcriptome data from the three crinoid species Antedon mediterranea, Florometra serratissima and Oligometra serripinna were also included. For the same reason transcriptome data from the brittle star Amphiura filliformis, Ophioderma brevispina and the hemichordate Schizocardium californicum were likewise analyzed. Obviously, transcriptome data can only demonstrate the presence of a gene but not its absence and their usefulness depends largely on the variety of tissues sampled and the expression levels of the genes of interest. Nevertheless, such data often provide additional sequences that even if they are incomplete, increase the robustness of sequence comparisons.

238 Insulin-like peptide precursors are typically characterized as having A, B and C domains that correspond to the A- and B-chains of insulin and the connecting peptide respectively. In IGF, D and $\mathrm{E}$ domains are also recognized, in which the $\mathrm{D}$ domain refers to the extension of the $\mathrm{A}$ chain and the $\mathrm{E}$ domain to part of the precursor after the D domain that is cleaved from IGF in the Golgi apparatus. For dilp7 orthologs it is appropriate to add an F (front) domain for the sequence in the N-terminal of the B-chain that in some peptides is not only larger, but also well conserved 244 (Fig. 1).

Previous work on insulin-related peptides in in echinoderms have identified two different types of insulin-like peptides, gonad-stimulating substances (GSS) and insulin-like growth insulin-like growth factors, but not GSS, are also present in hemichordates. While only a single 
249 IGF gene was found in the crinoids and hemichordates, other ambulacrarians have two such

250 genes (Figs. 2, S1, S2; Spreadsheet S1). These proteins have large C-terminal extensions that are

251 rich in charged amino acid residues, especially arginine and lysine, but also aspartic and glutamic

252 acid residues. A comparison of the protein sequences and cDNAs from human IGFs identifies

253 the exact separation between the D and E domains in these proteins (Humbel, 1990). However,

254 although the corresponding sequences of the hemichordate and echinoderm IGFs contain

255 numerous arginine and lysine residues (Figs. 2, S1, S2), there are no obvious convertase cleavage

256 sites as many potential arginine residues are succeeded by residues known to inhibit such

257 enzymes in vertebrates. It is thus not impossible that the D domains of these proteins are much

258 larger than in the vertebrate IGFs and, if so, likely contain numerous positively charged amino

259 acid residues. There are few transcriptome SRAs for specific tissues, however, the data that is

260 available, suggest that the IGFs are expressed by many tissues, with the ovary showing

261 significant expression. Patiria pectinifera is the only species with follicle cell specific SRAs and

262 IGF-1 is strongly expressed by these cells and is probably transferred to the oocyte (Spreadsheet

263 S2).

264 The GSS are known to induce oocyte maturation and ovulation in a two step process, where

265 GSS stimulates the follicle cells to produce 1-methyladenine which subsequently induces

266 resumption of meiosis in the oocyte and about 30 minutes later this is followed by ovulation

267 (Chiba, 2020). Interestingly, GSS was not found in either the genome nor the extensive

268 transcriptome data from the feather star Anneissia japonica and was similarly not encountered in

269 the transcriptomes of three other crinoids (Suppl data). Transcriptomes may miss the expression

270 of some genes, and large genome assemblies are never perfect. The short sequence reads in the

271 genomic SRAs from Anneissia were therefore also analyzed for the presence of GSS, but again

272 no evidence for such a gene was found. This peptide is thus likely absent from Anneissia and

273 perhaps all Crinoidea. In the Holothuroidea and the Asterozoa, but not the Echinoidea, this gene

274 is duplicated with the two paralogous peptides showing significant sequence variability (Figs. 3,

275 S3, S4; Spreadsheet S1). As for all these peptides and their putative receptors, expression data

276 are very limited, but in Apostichopus the two GSSs are differentially expressed, with GSS-1

277 being expressed at specific stages during embryonic development as well as by muscle and GSS-

2782 strongly expressed by both the ovary and the testes. Interestingly, in Holothuria scabra, it is

279 the ortholog of GSS-1 that has been tested for biological activity and induces ovulation (Chieu et 
280 al., 2019). This makes one wonder what the effects of GSS-2 on ovulation might be in this

281 species. However, Apostichopus was the only species where a significant GSS expression was

282 found in the gonads (Spreadsheet S2).

283 Two other insulin-like peptides are commonly present in both hemichordates and

284 echinoderms, including the Crinoidea. The first is an ortholog dilp7, which has a very

285 characteristic F domain while its A chain is also remarkably well conserved (Figs. 4, S5, S6;

286 Spreadsheet S1). The precursors of this peptide contain typical neuroendocrine KR convertase

287 sites and seem to have their highest expression in the nervous system, although expression also

288 occurs in other tissues. During embryogenesis dilp7 expression occurs relatively late

289 (Spreadsheet S2). The second peptide present in all ambulacrarians has been called octinsulin as

290 it has eight cysteine residues and is thus predicted to have four rather than three disulfide

291 bridges. In echinoderms octinsulin is a single copy gene, but hemichordates have several such

292 genes (Fig. 5, S7, S8; Spreadsheet S1). Octinsulin expression levels are the highest in nervous

293 tissue, and significant expression is also found in the gut and stomach of Strongylocentrotus and

294 Patiria pectinifera respectively. Although virtually absent from normal gut in Apostichopus, it

295 has significant expression during gut regeneration of this species (Spreadsheet S2).

296 The Asterozoa have genes coding for a fifth type of insulin, which is usually present in

297 multiple copies termed multinsulins. The predicted peptides share structural similarity with the

298 dilp7 orthologs; their genes have typically four coding exons rather than the two or three of the

299 other irp genes. The sprawl of these peptides is perhaps best illustrated by a phylogenetic tree

300 that suggests independent multiplication of these genes in several species (Fig. S10). Within a

301 single species the various multinsulins, thus, often seem more closely related to one another than

302 to their putative orthologs in other Asterozoa. Some of the multinsulins, like the octinsulins, have

303 acquired two additional cysteine residues and are thus predicted to have four disulfide bridges,

304 but the location of these additional cysteine residues differs from that in octinsulins (Figs. 6, 7,

305 S9, S10; Spreadsheet S1). Like dilp7, the multinsulins have typical neuroendocrine KR

306 convertase cleavage sites and can thus be expected to be expressed in neuroendocrine and/or

307 enteroendocrine cells; however, expression data on P. pectinifera suggest a relatively ubiquitous

308 expression in several tissues.

309 The genome assemblies of A. planci and Pisaster ochraceus show these genes to be

310 clustered in the genome and some RNAseq sequences suggests that at least on occasion coding 
311 exons from different genes may be combined (Fig. S10). This and the large numbers of SNPs

312 typically present in animals caught in nature and used for RNAseq preparation make it

313 impossible to reliably determine their exact numbers.

314 Genome assemblies allow identification of the introns in these genes. All insulin genes have

315 a characteristic phase 1 intron somewhere in their conceptual $\mathrm{C}$ domain. This is the only intron in

316 the coding sequences of the octinsulin and GSS genes. The IGF genes have a phase 0 intron near

317 the end of the coding sequence, and at least some of them have another phase 1 intron just after

318 the transcription start site. The genes coding for the dilp7 orthologs and multinsulins share an

319 additional phase 2 intron, and the multinsulin genes have yet another phase 1 intron. All these

320 introns appear perfectly conserved (Fig. 7).

321

322

Synteny of genes producing insulin-like peptides

323 In the Strongylocentrotus genome, all five genes are located on the same chromosome, with

324 the two IGF genes and those encoding octinsulin and dilp7 orthologs next to one another, and

325 GSS at a distance of 6,000,000 bp (base pairs). At least the Anneissia octinsulin and IGF genes

326 are likely located next to one another on the same chromosome also, as in the current genome

327 assembly two of the three coding exons of IGF and one of the two octinsulin coding exons are

328 located within about 10,000 bp. The three missing exons of these two genes are all located on

329 minicontigs of less than $2,000 \mathrm{bp}$, as is one of the coding exons for the dilp7 ortholog. The

330 contigs of the Lytechinus variegatus genome assembly are smaller and this may explain why in

331 this species the genes are located on three different scaffolds, with the two ILGF-like peptides

332 and the octinsulin together on a single contig. However in the recently published genome of the

333 closely related L. pictus (Warner et al., 2021) the dilp7 ortholog is also closely associated with

334 the other three genes. The GSS gene is on the same chromosome but at a distance of 28,000,000

$335 \mathrm{bp}$. In the Apostichus japonicus genome assembly the genes encoding the octinsulin and the two

336 IGF genes are located on the same contig, and the other genes each on a different one. In the

337 draft Holothuria glaberrima genome assembly only the two IGF genes are located on the same

338 contig, however in a single Oxford nanopore read (SRR9125585.2851.1) from H. scabra the

339 octinsulin, dilp7 and two IGF genes are located next to one another as well (Fig. 8).

340 Whereas the various Echinozoa genome assemblies suggest a certain degree of synteny with

341 regard to the various irp genes, the Asterozoa genomes show that such syntenty is disintegrating.

Peer] reviewing PDF | (2021:04:60199:2:0:REVIEW 22 Jun 2021) 
342 This is most clearly demonstrated in the genome assemblies from Pisaster ochraceus and

343 Acanthaster planci, where the scaffolds are much larger than from Patiria miniata. In these

344 species synteny is largely lost (Fig. 8). Interestingly the various multinsulin genes are present in

345 small clusters on different chromosomes in those species.

346

347 Sequence similarity tree peptides related to insulin

348 Peptides having the characteristic insulin signature are notoriously variable in their primary

349 amino acid sequences. Although the various residues allow one to align those sequences, such

350 alignments will not always yield reliable phylogenetic trees as the basic tenet of such analyses is

351 often not met. As an alternative I have proposed to use "sequence similarity trees". Such trees are

352 constructed using the same methods but do not pretend to illustrate phylogenetic relations, rather

353 similarities between the different proteins.

354 As the structures of the multinsulins are most similar to the dilp7 orthologs (Fig. 6), it is not

355 surprising that the sequence similarity tree (Fig. 9) groups the multinsulins with the dilp7

356 orthologs. The hypothesis that this structural similarity between these two types of peptides may

357 reflect a close evolutoinary relationship is reinforced by the presence of an intron in the genes

358 encoding these peptides but not in the genes encoding octinsulin, IGF and GSS (Fig. 7). The tree

359 also illustrates significant sequence similarity between GSS and the IGF.

360

361

Orthologs of receptors for irps: Receptor tyrosine kinase

A single insulin RTK gene was found in all species analyzed here. An alternatively spliced

363

form is present in Acanthaster and is likely commonly present in echinoderms (Spreadsheet S1).

364

Hundreds of ambulacrarian protein sequences were identified at NCBI using a BLAST search

365

with the S. kowalevskii protein kinase domain as a query. After aligning them with Clustal

366

omega the protein kinase domains were used to make a phylogenetic tree. Results revealed no

367

other known or predicted proteins with a similar protein kinase domain. The insulin RTK is

368

ubiquitously expressed (Spreadsheet S2).

369

370

Orthologs of receptors for irps peptides: LGRs

371

LGR sequences were obtained using the combination of genomic sequences and, where

372

available, transcriptome shotgun sequences and RNAseq SRAs. The latter were used to produce

PeerJ reviewing PDF | (2021:04:60199:2:0:REVIEW 22 Jun 2021) 
373 contigs using Trinity (Spreadsheet S1). Short read assemblers are good in combining sequences

374 into larger continuous ones, but they do produce artifacts, which are more easily obtained when

375 very similar sequences are present in multiple copies, such as the multinsulins, or the numerous

376 LDLa and LRR repeats. These repeats are usually individually coded by single exons that are

377 sometimes skipped, and when such skipped individual reads enter in the RNAseq SRA, incorrect

378 constructs are obtained. Furthermore, these repeats are present in numerous proteins, and from

379 time to time this leads to assembled sequences that are from mRNA species from different genes.

380 It is therefore to be expected that not all assembled transcripts, neither those in the databank nor

381 those produced here, will be correct. Some errors were corrected by challenging divergent

382 sequences that were discovered on comparing putative orthologs with one another. Other

383 differences could be confirmed as true differences, but it is not impossible that some errors

384 remain, particularly for those sequences that are incomplete. LGRs that might function as

385 receptors for the various irps were identified by their homology with such receptors from

386 vertebrates and arthropods. The transmembrane regions of the GPCRs don't have the assembly

387 problems of the LDLa and LRR repeats and are the most characteristic domain of the GPCRs.

388 This makes it easier to construct a phylogenetic trees for these receptors based on their

389 transmembrane regions than that it is to produce complete LGR transcripts.

390 Results show a surprisingly similar distribution of LGRs in the species studied. The tree

391 resolves two major branches, one for the glycoprotein hormone receptors, which itself is divided

392 in two subbranches, one for orthologs of the GPA2/GPB5 receptor - containing the receptors for

393 human TSH, FSH and LH - and a second one for the bursicon receptor orthologs. All species

394 studied are represented by one member on each of these two subbranches, except for Ophiothrix,

395 where the draft genome reveals two orthologs each for the bursicon and GPA2/GPB5 receptors

396 (Fig. 10). These are likely receptors for the bursicon and GPA2/GPB5 orthologs identified from

397 various echinoderm species (Semmens et al., 2016). It is interesting to see that whereas

398 vertebrates have different receptors for TSH, FSH and LH, most echinoderms have only one

399 GPA2/GPB5-receptor ortholog (Fig. S11), even though A. rubens has two GPA2 and three GPB5

400 orthologs (Semmens et al., 2016). The LGRs for the glycoproteins were included in the search

401 for putative receptors for the ambulacrarian irp LGRs in order to be sure that no such receptors

402 would be missed. 
The lower branches of the LGR phylogenetic tree are the ones of interest as they contain

404

405

406

407

408

409

410

411

412

413

414

415

416

417

418

419

420

421

422

423

424

425

426

427

428

429

430

431

432

receptors with irp ligands. It consists of three subbranches, that are characterized by Drosophila

LGR3 and LGR4 - the receptors for gonadulin and dilp7 respectively - and Periplaneta LGR5, an ortholog of Lymnaea GRL101. Here in all ambulacrarian species studied only one ortholog was found for each of them, despite extensive attempts to find additional LGRs in the various genomes and transcriptomes.

The GRL101 transmembrane regions puts it very close to vertebrate glycoprotein hormone and relaxin LGRs. LRRs are present in many different proteins, but when the LRR part of the Anneissia GRL101 (amino acid residues 576-717) is used as query in a protein BLAST against

human proteins, the glycoprotein hormone and relaxin receptors are identified as most similar to this ectodomain of GRL101, suggesting that similarity of the GRL101 receptors with vertebrate LGRs is not limited to the transmembrane region of this GPCR.

Sequence alignments of these GPCRs show strong sequence similarity (Figs. S12-S14), however the dil7 receptor ortholog varies more between species. A schematic representation of the the ectodomains of the LGRs on this second branch is drawn in Fig. 11. The orthologs of the dilp7 and gonadulin receptors each have a single LDLa repeat, except for the Patiria and Acanthaster orthologs of the dilp7 receptor which both have two LDLa repeats (Fig. S13). This additional LDLa is likely due to a relatively recent duplication of the LDLa since the two LDLa repeats have very similar amino acid sequences (Spreadsheet S1). All three receptors are expressed in the nervous system and the gonadulin receptor is well expressed in the gonads, both testis and ovary, and strongly so in the follicle cells of P. pectinifera (Spreadsheet 2).

\section{Discussion}

The genomic and transcriptomic data from both the hemichordates and the echinoderms show that these two groups share three irps (octinsulin, IGF and a dilp7 orthologs). IGF and dilp7 are orthologs of the arthropod peptides that together with gonadulin originated from a gene triplication. The structure of gonadulin is poorly maintained, even within insects (Veenstra, 2020b). The variable structure of gonadulin and its loss in many arthropod lineages suggests that the evolutionary pressure on gonadulin is weak. This may explain why the amino acid sequence of gonadulin looks significantly different from octinsulin. Nevertheless, there are two lines of

Peer] reviewing PDF | (2021:04:60199:2:0:REVIEW 22 Jun 2021) 
433 evidence that suggest that these peptides must be orthologs as well. For one, synteny of the 434 chromosome fragment containing these genes is conserved between the sea urchin

435 Strongylocentrotus purpuratus, the hemichordate Saccoglossus kowalevskii and the cockroach

436 Blattella germanica, suggesting that these peptides are likely orthologs. More importantly, all

437 ambulacrarians have an ortholog of the gonadulin receptor and the only plausible ligand for such

438 a receptor encoded by their genomes is octinsulin. Thus, the gene triplication previously reported

439 from arthropods must have occurred in a common bilaterian ancestor of the deuterostomes and 440 protostomes.

441 Crinoids have the simplest irp signaling system, one gene each for IGF, octinsulin and the 442 dilp7 ortholog. Their putative receptors - insulin RTK, GRL101, and the orthologs of the dilp7 443 and gonadulin receptors - similarly are also each coded by a single gene. The hemichordates 444 have a very similar repertoire, except that the octinsulin gene is systematically amplified and in 445 some species the dilp7 ortholog as well. It thus appears likely that the first deuterostome had a 446 single copy of each of these genes.

447 Within the echinoderms, the irp genes evolved considerably, as shown both by an increase in 448 their numbers and the loss of synteny. Whereas the feather stars appear to have only a single IGF 449 gene, all other echinoderms have two such genes and two novel irps, GSS and multinsulin, 450 appeared. The GSS sequences are most similar to those of IGF, suggesting that they evolved 451 from a gene duplication event from the IGF gene. Although some GSS genes are located on the 452 same chromosome as the other irps, they are not close to the IGF genes, indicating that the IGF453 GSS split was not a local duplication but may have been the result of an incorrectly repaired 454 chromosome break.

455 In the Asterozoa a fifth type of irp gene emerged, those that code for the multinsulins which 456 share significant sequence similarity with the dilp7 orthologs. The initial multinsulin gene must 457 thus have its origin in a gene duplication of the dilp7 ortholog gene, with which they also share a 458 characteristic intron. Later the multinsulin gene seems to have undergone several additional gene 459 duplications in this respect the multinsulins resemble the insect neuroendocrine irps.

460 The co-evolution of ligands and receptors allows one to assign the putative receptors for 461 gonadulin, the dilp7 ortholog and IGF as the orthologs of the receptors of their arthropod 462 orthologs. This allows the identification of the ambulacrarian LGRs that are the orthologs of the 
463 gonadulin and dilp7 receptors as likely receptors for octinsulin and the dilp7 respectively, as well 464 as the insulin RTK as a receptor for IGF.

465 The appearance of the multinsulins is not accompanied by the evolution of a novel insulin466 receptor. Some animals have multiple insulin RTKs, e.g. some arthropods have up to four such genes (Veenstra, 2020a,b), however, in spite of extensive searches for a second insulin RTK in ambulacrarian genomes, none was found. Searches for an additional LGR that might function as a receptor for the GSS and/or multinsulin were unsuccessful and this raises the question which receptors are activated by these peptides.

471 I have previously argued that the close chromosomal association of the IGF, gonadulin and dilp7 ortholog genes in basal insects suggests that they derived from a gene triplication (Veenstra, 2020b). There are possible scenarios that can explain how IGF and gonadulin came to respectively activate an RTK and an LGR. It is possible that the original irp activated an RTK and that an LGR was later acquired as a second receptor by gonadulin, alternatively the original irp activated an LGR and IGF acquired an RTK as a second receptor. Given the importance of insulin RTKs for growth in very basal metazoans, it is improbable that the original irp activated an LGR and that an RTK was acquired much later during evolution (see e.g. Mortzfeld et al., 2019). This indicates that an irp acquired an LGR as a second receptor and the question is whether this happened before or after the gene triplication that yielded IGF, gonadulin and dilp7. In both Saccoglossus and arthropods the IGF gene is in the middle of the three. This suggests that this represents the gene organization after the gene triplication and that the dilp7 and gonadulin orthologs each evolved independently from the original irp rather than that dilp7 evolved from gonadulin or vice versa. Had dilp7 originated from a gene duplication of gonadulin or the other way round, they also might have been more similar to one another than they are. The acquisition of a second receptor must be an extremely rare event. Since both gonadulin and dilp7 use an LGR this would mean that such an extremely rare event of the acquisition of a second receptor would have occurred not only twice, but even with a very similar receptor. Furthermore, some metazoans have an LGR that is closely related to the dilp7 and gonadulin LGRs suggesting that it could be an IGF receptor (see below). It is for these reasons that the author favors the

491 hypothesis that the original irp already acted on both an LRG and an RTK, but, clearly, this 492 remains a hypothesis. 
493

494

495

496

497

498

499

500

501

502

503

504

505

506

507

508

509

510

511

512

513

514

515

516

517

518

519

520

521

522

523

The binding of insulin and relaxin to their respective receptors has been resolved in much detail in the last couple of years. The effective binding and stimulation of insulin RTK by the small irp from the snail Conus to the RTK shows that a small irp can be an effective ligand for this receptor (Menting et al., 2015). On the other hand, the complex interaction of relaxin to its LGR makes it more difficult to imagine a smaller peptide as an effective ligand (Hoare et al., 2019). Furthermore, considering the well conserved F-domain of the dilp7 receptor orthologs it is likely that it is necessary for interaction with its LGR receptor. The loss of this structure in multinsulin suggests that it is unlikely to be a dilp7 receptor agonist. On the other hand, the poor sequence conservation in the various Drosophila irps that activate a single RTK is reminiscent of the large structural variability of the multinsulins. This seems to suggest that the multinsulins are RTK ligands rather than that they activate the LGR.

The emergence of the GSS is not accompanied by the evolution of a novel receptor for these irps. This can be explained by assuming that IGF acts on both the RTK and an LGR and that the GSS have lost their affinity for the LGR. This raises the question whether an IGF LGR might exist.

If there were an IGF LGR, one would expect it to be related to the gonadulin and dilp7 receptors. GRL101 appears to be a plausible candidate as its transmembrane regions are closely related to the receptors for gonadulin and dilp7. The ectodomain of GRL101 consists of two parts, a series of LRRs and a second series of LDLa's. In the related GPCRs, the LRRs are expected to bind with the insulin core of gonadulin and dilp7 orthologs, just like the human relaxin receptors (Hoare et al., 2019). When the LRR part of the Anneissia GRL101, the most basal echinoderm, was used as query for similar human proteins in a BLAST search, the glycoprotein hormone and relaxin receptors were identified as the most similar proteins. This shows that the resemblance of GRL101 to the other LGRs is not limited to the transmembrane regions and reinforces the hypothesis that the ligand of GRL101 has an insulin-like structure. GRL101 has a large number of LDLa's, the ligands of which are typically positively charged surfaces, which in the case of proteins consist of Lys and Arg residues (Daly et al., 1995; Prévost \& Raussens, 2004; Fisher, Beglova \& Blacklow, 2006; Yasui, Nogi \& Takagi, 2010; Dagil et al., 2013). Thus, the ligand of GRL101 may consist of two parts, an insulin-like structure and a piece with several positive charges that interact with the LDLa's. The C-terminal tails of the IGFs, whether from arthropods, echinoderms or hemichordates, are all rich in charged amino 
524 acid residues. The C-terminal tail of IGF with its numerous positively charged amino acid 525 residues might interact with the LDLa's of GRL101. I, therefore, posit that in those species that 526 have a GRL101 it functions as the second receptor for IGF. The absence of such a tail in GSS 527 would make it likely that it acts on the RTK rather than an IGF GPCR.

528 The suggestion that GSS activates the RTK goes against the hypothesis that these peptides 529 act through GPCRs. Indeed, it has recently been proposed that it is the ortholog of the dilp7 530 receptor that would be activated by the gonad stimulator in P. miniata (Mita et al., 2020). Given 531 the clear orthology of both dilp7 echinoderm orthologs with the Drosophila peptide and the 532 similar orthology between the dilp7 receptor and the echinoderm receptor, the conclusion that the 533 two constitute a functional ligand receptor combination seems inescapable. It was impossible to 534 find a GSS in either the genome assembly or the individual reads of all the genomic SRAs of 535 Anneissia japonica, yet it does have a dilp7 receptor ortholog; thus, if the dilp7 receptor were to 536 function as a GSS receptor, it most likely would not be an exclusive receptor. A priori, this does 537 not exclude the possibility that GSS could function as a ligand for the same receptor. As 538 mentioned above, since the dilp7 orthologs have well conserved F domains, one has to assume 539 that this domain is important for binding to its receptor. Since the F domain is absent from RTK 540 ligands, it is difficult to understand how a GSS that similarly lacks this domain would be able to 541 bind the dilp7 receptor. It would, thus, seem unlikely that peptides as different as GSS and dilp7 542 would be effective ligands of the same LGR. Furthermore, the GSS genes have been duplicated, 543 and their structures have diverged considerably. Those duplicate gonad stimulators are present in 544 many species and have not been selected against. Hence they must be phyisologically relevant 545 and able to interact with a receptor. Sharing a common evolutionary origin, the two gonad 546 stimulators would be expected to act either on the same or paralogous receptors, but the number 547 of putative echinoderm receptors for irps is limited, so they likely act on the same one. The same 548 arguments that were used to argue that the multinsulins are likely RTK agonists but not LGR 549 ligands, are therefore equally valid here and suggest that GSS is an RTK ligand.

550 Furhermore, the experimental evidence that GSS stimulates the ortholog of the dilp7 551 receptor is not convincing. The reported response to the dilp7 receptor when expressed in Sf9 552 cells is very weak and does not represent a typical response seen in this type of assay. Although 553 the authors have shown high affinity binding of GSS to the follicle cells, such high affinity 554 binding should also have been present in the Sf9 cells expressing the putative GSS receptor, but 
555 this was not reported. The follicle cell SRAs from which the putative GSS receptor was

556 identified contain large amounts of RNAseq reads for the gonadulin receptor, a receptor that is

557 more closely related to the vertebrate relaxin receptors than the dilp7 receptor, but surprisingly

558 the authors do not mention this receptor, which they must have found (Mita et al., 2020).

559 I suggest that initially there was an IGF-like hormone that activated both a GPCR and an

560 RTK. After two gene duplications some of the descendant ligands either lost their C-terminal

561 tails or one acquired a larger one and this allowed all three ligands to activate, at least initially,

562 the RTK while each acquired its own LGR. Later, some of the ligands may have lost their

563 affinity for one receptor. Since the primary amino acid sequence of gonadulin is very different

564 from that of the other irps, it likely lost its capacity to activate the RTK (Fig. 12).

565 Holometabolous insect species have lost GRL101 and hence in those species IGF, can only act

566 on the RTK. Under this hypothesis, the arginine-rich C-terminal tail would be useless in such

567 insect species; in higher flies, such as Drosophila, it was indeed lost (Veenstra, 2020b). In

568 vertebrates, there is no GRL101, and so IGF can only activate the two RTKs, while the relaxin

569 related peptides are not known to interact with RTK. The presence of a similar arginine-rich E

570 domain in the vertebrate IGF precursors might thus be an evolutionary relict.

571 This scheme raises the question as to how the functions of these two receptors activated by

572 IGF might differ. IGF and the Drosophila irps stimulate growth, the echinoderm GSS stimulates

573 oocyte maturation and ovulation (Mita et al., 2009), relaxin and INSL3 affet various

574 developmental and reproductive processes (Ivell et al., 2020; Esteban-Lopez \& Agoulnik, 2020),

575 gonadulin is expressed by the gonads as well as the imaginal discs in flies (Garelli et al., 2012;

576 Liao \& Nässel, 2020; Veenstra, 2020b; Veenstra et al., 2021), and dilp7 is expressed in a sex

577 specific manner (Miguel-Aliaga, Thor \& Gould, 2008; Yang et al., 2008; Castellanos, Tang \&

578 Allan, 2013). These hormones stimulate growth, development and reproduction, processes that

579 are intimately linked; without growth and development reproduction is impossible and growth

580 without reproduction is useless in sexually reproducing species. On the other hand, resources

581 used for growth and development can not be used for reproduction or vice versa.

582 Growth is rarely a linear process independent of development; animals are not only getting

583 bigger, but they also mature into adults. Metamorphosis is markedly different between hemi- and

584 holo-metabolous insect species. Every time a cockroach nymph molts, it becomes a little more

585 adult, however during the first molts of a caterpillar the insects mainly become bigger, it is only 
586 when it molts into a pupa that it significantly changes its morphology. Cockroaches have

587 GRL101; caterpillars don't. This suggests that the RTK might be more directed toward linear

588 growth, or allow growth by increasing uptake of resources, such as glucose and amino acids,

589 while the LGRs might be more important for insuring that the animal develops into an adult and

590 becomes sexually competent. Both holometabolous insects and vertebrates have lost GRL101

591 and use steroid hormones to induce sexual maturation. Interestingly, in vertebrates, the

592 production of steroid hormones is controlled by glycoprotein hormones, the second group of

593 ligands for LGRs.

594 It is plausible that IGF in an early bilaterian was produced by the tissue that stored energy

595 and perhaps even protein as insects do in the form of storage proteins (Haunerland, 1996).

596 Production and release of IGF might have happened when the animal had sufficient resources to

597 allow for growth and/or reproduction. In arthropods, growth has become a discontinuous process

598 in which a new cuticle needs to be made before molting can take place. In those species, IGF

599 produced by the fat body may well be the essential growth hormone. However, if the animal is

600 suddenly starved, IGF would no longer be released. If formation of a new cuticle is too advanced

601 to be interrupted, this becomes problematic. It may have obliged the brain to take at least partial

602 control of growth away from the fat body by releasing one or more of the neuroendocrine irps to

603 force growth and molting to proceed. It is possible that this achieved by simultaneously reducing

604 growth of organs that are needed for (sexual) maturation but not essential for immediate survival,

605 like the gonads. This could be how the neuroendocrine insect irps initially evolved. In

606 echinoderms, IGF probably stimulates growth of the follicles and oocytes, but the final growth

607 spurt, the one that permits resumption of meiosis in the oocytes and subsequent ovulation, is

608 delayed until optimal conditions to do so prevail. When the time and place are right, the nervous

609 system releases GSS likely in large amounts to finish the maturation process and induce

610 ovulation. In vertebrates, growth and the release of IGF has also been brought under control of

611 the brain but more forcefully by bringing IGF secretion by the liver under control of growth

612 hormone. Whereas in an early ancestor high plasma concentrations of glucose might have led to

613 secretion of IGF, this is no longer the case. Here insulin may have evolved to insure that plasma

614 concentrations of glucose are kept sufficiently low by insuring its absorption by tissues in order

615 to avoid it loss by excretion. In the three cases these peptides have very different functions,

616 ovulation in echinoderms, sparing glucose in vertebrates and rescuing interrupted growth in 
617 insects. It is plausible then that these hormones each evolved from a non-local IGF gene

618 duplication and that they are thus not proper orthologs but evolved by convergent evolution. This

619 hypothesis would explain, why there is no insulin gene located near the IGF,

620 octinsulin/gonadulin and dilp7 triplet in cockroaches, echinoderms and hemichordates, even

621 though insulin - and other peptides such as the insect neuroendocrine insulin-like peptides and

622 GSS - almost certainly evolved from IGF much later.

623

\section{Conclusions}

625 The gene triplication previously reported from arthropods must have occurred in a common

626 bilaterian ancestor of the deuterostomes and protostomes. The hypothesis that IGF in an ancestral

627 bilaterian used both a GPCR and an RTK may explain the combination of echinoderm irps and

628 putative insulin receptors. This hypothesis implies that insulin is not a hormone that evolved

629 before the split between protostomes and deuterostomes, but that insulin-like peptides evolved

630 independently in different metazoan clades as miniature copies of IGF capable to activate the

631 RTK but unable to stimulate the LGR.

632

633

\section{Acknowledgements}

This manuscript benefited from the critical contributions of an editor and two reviewers for which I am most grateful. Work like this is only possible because others made their transcriptome and genomic sequences publicly available. I express my sincere gratitude to all of 637 them.

638

639

\section{References}

640

641

642

643

644

645

646

647

648

649

650
Almagro Armenteros JJ, Tsirigos KD, Sønderby CK, Petersen TN, Winther O, Søren Brunak S, von Heijne G, and Nielsen H. 2019. SignalP 5.0 improves signal peptide predictions using deep neural networks. Nat Biotechnol. 37:420-423, doi:10.1038/s41587-019-0036-z.

Castellanos MC, Tang JC, Allan DW. 2013. Female-biased dimorphism underlies a femalespecific role for post-embryonic ilp7 neurons in Drosophila fertility. Development. 140:39153926. doi: 10.1242/dev.094714.

Chiba K, 2020. Oocyte maturation in starfish. Cells 9, 476. doi:10.3390/cells9020476. 
651 Chieu HD, Turner L, Smith MK, Wang T, Nocillado J, Palma P, Suwansa-Ard S, Elizur A, 652 Cummins SF. 2019. Aquaculture breeding enhancement: Maturation and spawning in sea 653 cucumbers using a recombinant relaxin-like sonad-stimulating peptide. Front Genet. 10:77. doi:

65410.3389 /fgene.2019.00077.

655

656

657

Colombani J, Andersen DS, Boulan L, Boone E, Romero N, Virolle V, Texada M, Léopold P. 2015. Drosophila Lgr3 couples organ growth with maturation and ensures developmental

658

659

660

Dagil R, O'shea C, Nykjær A, Bonvin AM, Kragelund BB. 2013. Gentamicin binds to the

661 megalin receptor as a competitive inhibitor using the common ligand binding motif of

662

663 complement type repeats insight from the NMR structure of the 10th complement type repeat domain alone and in complex with gentamicin. J. Biol. Chem. 288, 4424-4435. doi:

664 10.1074/jbc.M112.434159.

665

666

667

Daly NL, Scanlon MJ, Djordjevic JT, Kroon PA, Smith R. 1995. Three-dimensional structure of a cysteine-rich repeat from the low-density lipoprotein receptor. Proc Natl Acad Sci U S A.

668

669

670

Davidson PL, Guo H, Wang L, Berrio A, Zhang H, Chang Y, Soborowski AL, McClay DR, Fan

671 G, Wray GA. 2020. Chromosomal-level genome assembly of the sea urchin Lytechinus

672

673

674

675

676

677

678

679 variegatus substantially improves functional genomic analyses. Genome Biol Evol. 12:10801086. doi: $10.1093 /$ gbe/evaa101.

Devi L. 1991. Consensus sequence for processing of peptide precursors at monobasic sites. FEBS Lett 280:189-194. doi: 10.1016/0014-5793(91)80290-j.

Esteban-Lopez M, Agoulnik AI, 2020. Diverse functions of insulin-like 3 peptide. J Endocrinol. 247:R1-R12. doi: 10.1530/JOE-20-0168.

680

681 Garelli A, Gontijo AM, Miguela V, Caparros E, Dominguez M. 2012. Imaginal discs secrete

682

683

684 insulin-like peptide 8 to mediate plasticity of growth and maturation. Science. 336:579-582. doi: 10.1126/science. 1216735 .

Garelli A, Heredia F, Casimiro AP, Macedo A, Nunes C, Garcez M, Dias ARM, Volonte YA, Uhlmann T, Caparros E, Koyama T, Gontijo AM. 2015. Dilp8 requires the neuronal relaxin receptor Lgr3 to couple growth to developmental timing. Nat Commun. 6:8732. doi:

$68810.1038 /$ ncomms9732.

689

690 Fisher C, Beglova N, Blacklow SC. 2006. Structure of an LDLR-RAP complex reveals a general 691 mode for ligand recognition by lipoprotein receptors. Molecular Cell 22, 277-283. doi:

$692 \quad 10.1074 /$ jbc.M1 12.434159.

693

694 Grabherr MG, Haas BJ, Yassour M, Levin JZ, Thompson DA, Amit I, Adiconis X, Fan L, 695 Raychowdhury R, Zeng Q, Chen Z, Mauceli E, Hacohen N, Gnirke A, Rhind N, di Palma F, 696 Birren BW, Nusbaum C, Lindblad-Toh K, Friedman N, Regev A. 2011. Full-length 
697 transcriptome assembly from RNA-Seq data without a reference genome. Nat Biotechnol.

698 15;29:644-652. doi: 10.1038/nbt.1883.

699

700

701

Hall MR, Kocot KM, Baughman KW, Fernandez-Valverde SL, Gauthier MEA, Hatleberg WL, Krishnan A, McDougall C, Motti CA, Shoguchi E, Wang T, Xiang X, Zhao M, Bose U, Shinzato

702

703 C, Hisata K, Fujie M, Kanda M, Cummins SF, Satoh N, Degnan SM, Degnan BM. 2017. The crown-of-thorns starfish genome as a guide for biocontrol of this coral reef pest. Nature.

704

705

706 544:231-234. doi: 10.1038/nature22033.

Haunerland NH, 1996. Insect storage proteins: gene families and receptors. Insect Biochem Mol Biol. 26:755-65. doi: 10.1016/s0965-1748(96)00035-5.

708

Hoare BL, Bruell S, Sethi A, Gooley PR, Lew MJ, Hossain MA, Inoue A, Scott DJ, Bathgate

710 RAD.2019. Multi-component mechanism of H2 Relaxin binding to RXFP1 through NanoBRET kinetic analysis. iScience. 2019 Jan 25;11:93-113. doi: 10.1016/j.isci.2018.12.004.

714

715

Hsueh AJW, Feng Y, 2020. Discovery of polypeptide ligand-receptor pairs based on their coevolution. FASEB J. 34:8824-8832. doi: 10.1096/fj.202000779R.

Humbel RE, 1990. Insulin-like growth factors I and II. Eur J Biochem. 190:445-62. doi: 10.1111/j.1432-1033.1990.tb15595.x.

718

719

Imambocus BN, Wittich A, Tenedini F, Zhou F, Hu C, Sauter K, Varela EM. Herédia F, 720 Casimiro AP, Macedo A, Schlegel P, Yang CH, Miguel-Aliaga I, Pankratz MJ, Gontijo AM, 721

722

723

724

725

726

727

728

729

730

731

732

733

734

735

736

737

738

739

740

Cardona A, Soba P, 2020. Discrete escape responses are generated by neuropeptide-mediated circuit logic. bioRxiv preprint doi:10.1101/2020.09.22.307033.

Ivell R, Alhujaili W, Kohsaka T, Anand-Ivell R. 2020. Physiology and evolution of the INSL3/RXFP2 hormone/receptor system in higher vertebrates. Gen Comp Endocrinol. 299:113583. doi: 10.1016/j.ygcen.2020.113583.

Jo J, Oh J, Lee HG, Hong HH, Lee SG, Cheon S, Kern EMA, Jin S, Cho SJ, Park JK, Park C. 2017. Draft genome of the sea cucumber Apostichopus japonicus and genetic polymorphism among color variants. Gigascience. 6:1-6. doi: 10.1093/gigascience/giw006.

Liao S, Nässel DR. 2020. Drosophila insulin-like peptide 8 (DILP8) in ovarian follicle cells regulates ovulation and metabolism. bioRxiv. doi: 10.1101/2020.05.02.073585.

Lin M, Mita M, Egertová M, Zampronio CG, Jones AM, Elphick MR., 2017. Cellular localization of relaxin-like gonad-stimulating peptide expression in Asterias rubens: New insights into neurohormonal control of spawning in starfish. J Comp Neurol. 525:1599-1617. doi: $10.1002 /$ cne. 24141 .

Linneweber GA, Jacobson J, Busch KE, Hudry B, Christov CP, Dormann D, Yuan M, Otani T, Knust E, de Bono M, Miguel-Aliaga I., 2014. Neuronal control of metabolism through nutrient-

742 dependent modulation of tracheal branching. Cell 16;156:69-83. doi: 10.1016/j.cell.2013.12.008. 
743

744

745

746

747

748

749

750

751

752

753

754

755

756

757

758

759

760

761

762

763

764

765

766

767

768

769

770

771

772

773

774

775

776

777

778

779

780

781

782

783

784

785

786

787
Menting JG, Gajewiak J, MacRaild CA, Chou DH, Disotuar MM, Smith NA, Miller C, Erchegyi J, Rivier JE, Olivera BM, Forbes BE, Smith BJ, Norton RS, Safavi-Hemami H, Lawrence MC., 2015. A minimized human insulin-receptor-binding motif revealed in a Conus geographus venom insulin. Nat Struct Mol Biol. 23:916-920. doi: 10.1038/nsmb.3292.

Miguel-Aliaga I, Thor S, Gould AP. 2008. Postmitotic specification of Drosophila insulinergic neurons from pioneer neurons. PLoS Biol 6: e58. doi:10.1371/journal.pbio.0060058.

Mirabeau O, Joly JS. 2013. Molecular evolution of peptidergic signaling systems in bilaterians. Proc Natl Acad Sci U S A. 110: E2028-37. doi: 10.1073/pnas.1219956110.

Mita M, Yoshikuni M, Ohno K, Shibata Y, Paul-Prasanth B, Pitchayawasin S, Isobe M, Nagahama Y. 2009. A relaxin-like peptide purified from radial nerves induces oocyte maturation and ovulation in the starfish, Asterina pectinifera. Proc Natl Acad Sci U S A. 106:9507-12. doi: 10.1073/pnas.0900243106.

Mita M, Matsubara S, Osugi T, Shiraishi A, Wada A, Satake H. 2020. A novel G proteincoupled receptor for starfish gonadotropic hormone, relaxin-like gonad-stimulating peptide. PLoS One. 15:e0242877. doi: 10.1371/journal.pone.0242877.

Mortzfeld BM, Taubenheim J, Klimovich AV, Fraune S, Rosenstiel P, Bosch TCG. 2019. Temperature and insulin signaling regulate body size in Hydra by the Wnt and TGF-beta pathways. Nat Commun. 10:3257. doi: 10.1038/s41467-019-11136-6.

Perillo M, Arnone MI. 2014. Characterization of insulin-like peptides (ILPs) in the sea urchin Strongylocentrotus purpuratus: insights on the evolution of the insulin family. Gen Comp Endocrinol. 205:68-79. doi: 10.1016/j.ygcen.2014.06.014.

Prévost M, Raussens V. 2004. Apolipoprotein E-low density lipoprotein receptor binding: study of protein-protein interaction in rationally selected docked complexes. Proteins 55:874-84. doi: 10.1002 /prot. 20080 .

Price MN, Dehal PS, Arkin AP. 2010. FastTree 2--approximately maximum-likelihood trees for large alignments. PLoS One. 5:e9490. doi: 10.1371/journal.pone.0009490.

Rholam M, Brakch N, Germain D, Thomas DY, Fahy C, Boussetta H, Boileau G, Cohen P. 1995. Role of amino acid sequences flanking dibasic cleavage sites in precursor proteolytic processing. The importance of the first residue C-terminal of the cleavage site. Eur J Biochem. 227:707-714. doi: 10.1111/j.1432-1033.1995.tb20192.x.

Ruiz-Ramos DV, Schiebelhut LM, Hoff KJ, Wares JP, Dawson MN. 2020. An initial comparative genomic autopsy of wasting disease in sea stars. Mol Ecol. 29:1087-1102. doi: 10.1111/mec.15386. 
788 Rutherford K, Parkhill J, Crook J, Horsnell T, Rice P, Rajandream MA, Barrell B. 2000. Artemis: sequence visualization and annotation. Bioinformatics 16:944-5. doi:

790

791

792

793

794

795

796

797

798

799

800

801

802 10.1093/bioinformatics/16.10.944.

Sea Urchin Genome Sequencing Consortium. 2006. The genome of the sea urchin Strongylocentrotus purpuratus. Science 314: 941-952.

Semmens DC, Mirabeau O, Moghul I, Pancholi MR, Wurm Y, Elphick MR. 2016.

Transcriptomic identification of starfish neuropeptide precursors yields new insights into neuropeptide evolution. Open Biol. 6:150224. doi: 10.1098/rsob.150224.

Sievers F, Wilm A, Dineen D, Gibson TJ, Karplus K, Li W, Lopez R, McWilliam H, Remmert M, Söding J, Thompson JD, Higgins DG. 2011. Fast, scalable generation of high-quality protein multiple sequence alignments using Clustal Omega. Mol Syst Biol. 7:539. doi:

10.1038/msb.2011.75.

803

804

Simakov O, Kawashima T, Marlétaz F, Jenkins J, Koyanagi R, Mitros T, Hisata K, Bredeson J,

805 Shoguchi E, Gyoja F, Yue JX, Chen YC, Freeman RM Jr, Sasaki A, Hikosaka-Katayama T, Sato

806

807 A, Fujie M, Baughman KW, Levine J, Gonzalez P, Cameron C, Fritzenwanker JH, Pani AM, Goto H, Kanda M, Arakaki N, Yamasaki S, Qu J, Cree A, Ding Y, Dinh HH, Dugan S, Holder M, Jhangiani SN, Kovar CL, Lee SL, Lewis LR, Morton D, Nazareth LV, Okwuonu G,

810 Santibanez J, Chen R, Richards S, Muzny DM, Gillis A, Peshkin L, Wu M, Humphreys T, Su

811 YH, Putnam NH, Schmutz J, Fujiyama A, Yu JK, Tagawa K, Worley KC, Gibbs RA, Kirschner

812

813

814 MW, Lowe CJ, Satoh N, Rokhsar DS, Gerhart J. 2015. Hemichordate genomes and deuterostome origins. Nature. 527:459-465. doi: 10.1038/nature16150.

815 Smith MK, Chieu HD, Aizen J, Mos B, Motti CA, Elizur A, Cummins SF. 2019. A Crown-of-

816 and ovulation. Gen Comp Endocrinol. 281:41-48. doi: 10.1016/j.ygcen.2019.05.009.

Tensen CP, Van Kesteren ER, Planta RJ, Cox KJ, Burke JF, van Heerikhuizen H, Vreugdenhil E. 1994. A G protein-coupled receptor with low density lipoprotein-binding motifs suggests a role for lipoproteins in G-linked signal transduction. Proc Natl Acad Sci U S A. 91:4816-4820. doi: 10.1073/pnas.91.11.4816.

Vallejo DM, Juarez-Carreño S, Bolivar J, Morante J, Dominguez M. 2015. A brain circuit that synchronizes growth and maturation revealed through dilp8 binding to Lgr3. Science. 50:aac6767. doi: 10.1126/science.aac6767.

Veenstra JA. 2000. Mono- and dibasic proteolytic cleavage sites in insect neuroendocrine peptide precursors. Arch Insect Biochem Physiol. 43:49-63. doi: 10.1002/(SICI)15206327(200002)43:2<49::AID-ARCH1>3.0.CO;2-M.

Veenstra JA. 2020a. Gonadulins, the fourth type of insulin-related peptides in decapods. Gen Comp Endocrinol. 296:113528. doi: 10.1016/j.ygcen.2020.113528. 
834 Veenstra JA. 2020b. Arthropod IGF, relaxin and gonadulin, putative orthologs of Drosophila 835 insulin-like peptides 6,7 and 8, likely originated from an ancient gene triplication. 10: e9534. 836 doi: $10.7717 /$ peerj.9534.

837

838 Veenstra JA, Rombauts S, Grbić M. 2012. In silico cloning of genes encoding neuropeptides, 839 neurohormones and their putative G-protein coupled receptors in a spider mite. Insect Biochem 840 Mol Biol. 42:277-295. doi: 10.1016/j.ibmb.2011.12.009.

841

842

843

Veenstra JA, Leyria J, Orchard I, Lange A. 2021. Identification of gonadulin and insulin-like growth factor from migratory locusts and their importance in reproduction in Locusta

844

845

846

847 migratoria. Front Endocrinol.12: 693068. doi: 10.3389/fendo.2021.693068.

Warner JF, Lord JW, Schreiter SA, Nesbit KT, Hamdoun A, Lyons DC. 2021. Chromosomallevel genome assembly of the painted sea urchin Lytechinus pictus, a genetically enabled model system for cell biology and embryonic development. Genome Biol Evol:evab061. doi:

849 10.1093/gbe/evab061.

850

851

852

853

854

855

856

857

Yang CH, Belawat P, Hafen E, Jan LY, Jan YN. 2008. Drosophila egg-laying site selection as a system to study simple decision-making processes. Science 319: 1679-1683. doi: 10.1126/science. 1151842 .

Yasui N, Nogi T., Takagi J. 2010. Structural basis for specific recognition of reelin by its receptors. Structure 18, 320-331. doi: 10.1016/j.str.2010.01.010.

Zhang X, Sun L, Yuan J, Sun Y, Gao Y, Zhang L, Li S, Dai H, Hamel JF, Liu C, Yu Y, Liu S, Lin W, Guo K, Jin S, Xu P, Storey KB, Huan P, Zhang T, Zhou Y, Zhang J, Lin C, Li X, Xing L, Huo D, Sun M, Wang L, Mercier A, Li F, Yang H, Xiang J. 2017. The sea cucumber genome 861 provides insights into morphological evolution and visceral regeneration. PLoS Biol. 15:e2003790. doi: 10.1371/journal.pbio.2003790.

863 


\section{Figure 1}

Domains of insulin/IGF-related peptides.

Human insulin and IGF and Drosophila dilp7 are aligned and the different domains that are recognized in the precursors of these peptides are indicated. In insulin the domain borders are the convertase cleavage sites that are hihglighted in red. The A- and B-domains of insulin correspond to the A- and B-chains of insulina and the C-domain to the connecting peptide. Although IGF consists of a single protein chain due to its strong sequences similarity to insulin the A- and B-domains correspond to homologous regions of those domains in insulin, while the C-domain is the sequence between the A- and B-domains. In insulin there is only a single amino acid residues after the last cysteine residue, but in IGF there is a longer sequence, that has been called the D-domain. The IGF precursor is cleaved by furin in the Golgi apparatus and the sequence that is removed has been called the E-domain. Dilp7 is only known from nucleotide sequences, it is unknown how the precursor is exactly processed. Nevertheless, the presence of putative convertase cleavage sites, highlighted in red, suggests the presence of A-, B- and C-domains quite similar to those in insulin. However, unlike insulin or IGF, the putative B-chain of dilp7 has a long N-terminal extension that I propose to call the F-domain. The latter is well conserved in dilp7 orthologs from other bilaterians (Fig. 4). 


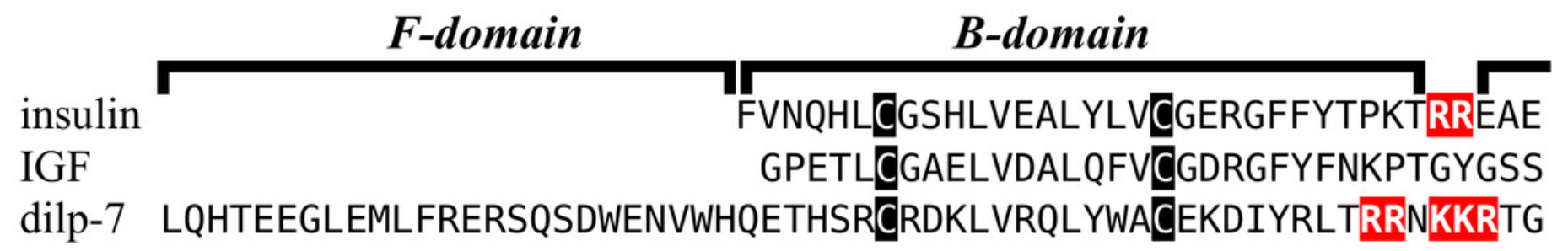

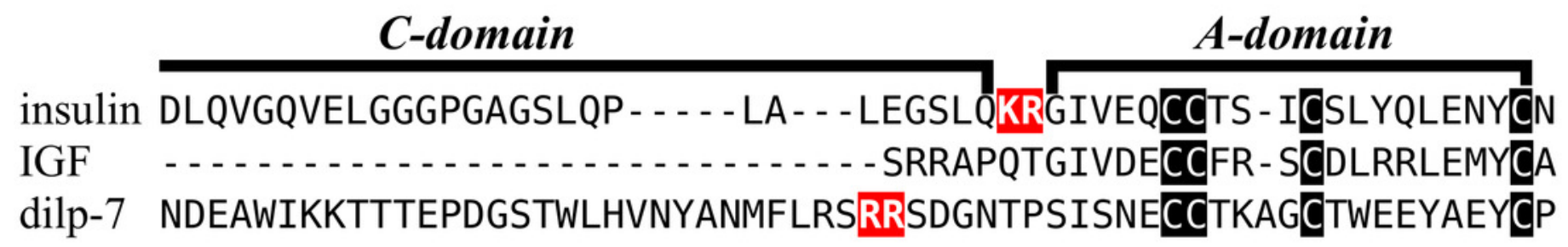

insulin

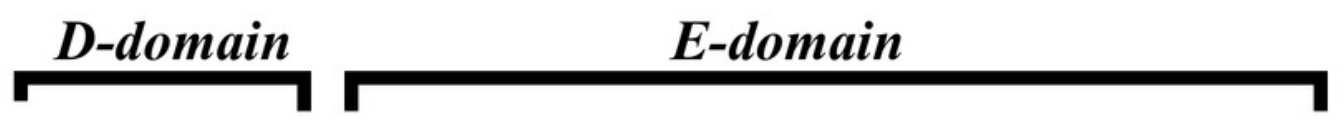

IGF PLKPAKSARSVRAQRHTDMPKTQKYQPPSTNKNTKSQRRKGSTFEERK

dilp-7 SNKRRNHY 


\section{Figure 2}

Sequences of selected ambulacrarian IGF.

Partial IGF sequences from selected ambulacrarians are illustrated to show their sequence similarity. The A-, B- and C-domains of the insulin core are aligned, but not the putative Dand $\mathrm{E}$ - domains, as their amino acid sequence is only conserved in closely related species (Fig. S1). Not aligning D- and E- domains allows the visualization the context of putative convertase cleavage sites. None of the arginine or lysine residues conform to a typical arthropod or vertebrate convertase cleavage site. Although the sequence of the latter part of the IGF precursors is not well conserved, all of them are rich in positively charged amino acid residues. Conserved cysteine residues are indicated in red, conserved amino acid residues are highlighted in black and conserved substitutions in grey. The arginine and lysine residues in the D- and E- domains are highlighted in blue. 
Anneissia

Strongylocentrotus-1

Strongylocentrotus -2

Apostichopus-1

Apostichopus-2

Acanthaster-1

Acanthaster-2

Ophiothrix-1

Ophiothrix-2

Saccoglossus

Ptychodera

Schizocardium

\section{Anneissia}

Strongylocentrotus-1

Strongylocentrotus-2

Apostichopus-1

Apostichopus-2

Acanthaster-1

Acanthaster -2

Ophiothrix-1

Ophiothrix-2

Saccoglossus

Ptychodera

Schizocardium

\section{Anneissia}

Strongylocentrotus -1 Strongylocentrotus-2 Apostichopus-1

Apostichopus-2

Acanthaster-1

Acanthaster-2

Ophiothrix-1

Ophiothrix-2

Saccoglossus

Ptychodera

Schizocardium

\section{Anneissia}

Strongylocentrotus -1 Strongylocentrotus-2 Apostichopus-1 Apostichopus-2 Acanthaster-1 Acanthaster-2 Ophiothrix-1 Ophiothrix-2 Saccoglossus Ptychodera

Schizocardium

Anneissia

Strongylocentrotus-1 Strongylocentrotus -2 Apostichopus-1 Apostichopus-2 Acanthaster -1 Acanthaster-2 Ophiothrix-1 Ophiothrix-2 Saccoglossus Ptychodera Schizocardium
QPNHVRRYCGS ELT S ELERRCALKGGFN SPKKQESP-- - - - - - - - - - - - $---S F$ P LL CGQELVKAV VAAV $----S F R L$ - - SGORY $----A Q R Y$ C GTNLADALR IV $---A V I Q V$ CGNDLLDALKSV - - - WQRI C EE QLVETVS IV $----W Q R L$ $----S Y L$ - - -WDKL C GR TLVDVLAL I - - -WDRL CGR SLADMLALV - - -WDKL CGRTLADMLSLV
---------YLWNQE KR I EATS-----------TERAKE INIVYE ----KRSAG IFELETRAKTFLKSGISRGETRRSKRGARTGLIVTE - - -AQKD SP I VP H HVAS SF L GS S S -ASAH SRQRRRVRT GQI VNE - - - VSRSPELTEE RAN SF LTNE---- - -RTRKTRRT GRIVTE --------PEVI P RQRAS SFITTDS---ENHHPRRLRRGTGIVTE

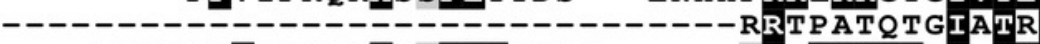
----KREAELFQDERTAK SF LGTH I G------SRQRRRTGRIATE SDTNNAE SNPF RGESEAKSF L GL--------SRQKRRT GRI VHE IVYSFLTDPPLLTERQAKTET-KSG----------RTRTGKIVTE $---K V K R E S P F R S G M E A N D F F$ GN I S-SKEKRRQRRRS GS GKI VDE -KSRRARE TVEATQE EANGFF GVG---S--GRTKRRRGS GI I VVE -- - LPRE TIETQEDAH KEFGASV-FG--ERTQRRRGS GLIVAEC

CHSACTEAFIDS
CINRCSVSHLES
CDKECSNNIMES
CDNPCSQRNLES
CEKACDREVIET
CISYCETSVLEK
CEKVCSYDIVES
CNN ICNYRIIES
CDNHCDMQIIES
CHQACDYTTLES
CDKICDYSTIES
CEKSCDYATIES

FCLS SNKDEDTTVESDTVETTTITGKKRKP TRKPKNP LKSRKKPKGSSE INSEQSASN CNPLPP DAVHDAEVH IRLERSAEEDADEGRPQDGPSQLDTATGTVPETEMSETRGRV CNRRTPEVPPESAISENPSEEITEDSTLRTDGESTEIRTDTNPATNLEVPSPDANTP Y CNVATTQTTEIPTELTTEGTTTEPAASPRRNSRNIEADGTAAAAGGGSGQGNGRGKG CNPHVTP TLALASLVTSLMTKSPTPPSSEPSSSSSSSS SRNEDKFPMTDNALGEDY Y CNPPSTSQSQTAAAP PRITTTPDERRANE IVVDETGQT GNTNSQMLRGGNAMGAGSR $Y$ CNP WPVVEDRDDP MLAP VAP GRVRQDKS ADAD L L LRPD IAE I SE DKSS L LRQAAEKD $Y$ CNP WPTT TTTATTTQSPEPI P NEQEGGYLTDE I QMKH I TRGQEDNSVDILSEGSDLR $Y$ CAP LQEG $Q V R F$ T SRNLDFVNEANNVVEEP SVRVP QQVE ENRIVE E TVP YVS $Q A$ IVGE Y CAP LPEGVVADDSIKRF L SQSF GNDFKDTANEDKLE IVTVVRP S HDEMDGTETRIED Y CAPWPKD IDP AKKI EGFKEGTWEEEDYHRKY HPESVEQPNANPEEPTPEPTTTDLDK Y CAPWP KDMDPALRF AGFKYGSWEDEDYYRKYHPEEFTQPDLTTWIASTDSANHDEHF

TELP SQTE P TKDKNGRGDKNKKDKC NKKSRDKNNKP CRRKSRKD SRRKNRKKNKKNKP RIDAVEKVLSERL I P T TTGSSP SP SRKKPRKDKSERRNSSREAKQARREERRRNRER DATATSDVEQPRSDNTTAVEKPRKKDNGKGKNSSLESSTKKNRT SKGMSKEDRRRIAS KGRH GRGNRREQDQTVDVTSAETEGNTEPPRPNQQENNEDNRGTP DQSEERPRDRCRG EGPTNEGP LTS GEPTPTENRI SNGPRGP S NAS SLELPTRTSTATTNSSRIVTEGAHL ANGTKAP TEVVDGRSDDDDDAAGE INTSERVGSLTEPDEETGRDVATNRP HKT HSK EP IDDLDTLENEYAD GGNVML QARE GVKEEGAEL GKEME EGGEKMP F P EVVP TKKRRR DE TP MP T GRA T G GRS PQL GHD SADVDS GF HRF GD I GAEVEE SDS T I DNPSSDR---TTSDGF DWDSDVSETHN I LNG GGDMY INDQPRDDP SENDEEH I R KEKS I IKQINVTES NEHVTP P TKP DVITETSSI I LDD INVNKQ I I SSNT SVEVKSKAGN TKP KREKKDRDNS SLESESRDNVD IEESRSKDKSAESEESVTENDDLKSEETNDNQDEYSREEYLGRDKGP TTATPSEETTSSENGEHIKTVNKEDDTQVTGTHELEKDHKFAEYWMNEDKMSRKHKKA

TRRP KRWD SET T TLSDF LF SQRF LQRA YDSD I DVDE I T TEFGVVPEEDISSS L SEEEL

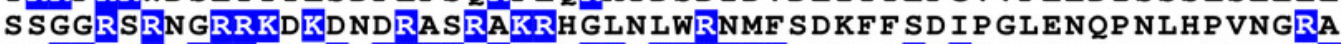
DERRASRERKKEL SRERRKRLKLQQRKDKKKKKRL E SAERNRGTD HMGL SED STLIAR SKKKGKCRNQDRVEEEPTQDRIEEEPTTSREVSSTDGLSRERGSGSGGGRNRGNGKGK AESSDQS LEDTDSESEAP TKGAS HERTRKKQKKQRTRP PKKPKKL SRERKERKKKKE RSKNNRT SKS ERRRRRTNRRRS S ERRML S SERKREDATRKLRRKEQRLSRKQP HSNKR VEGRRSRENSRDRNGKSEGKSKRKSGSREGGRSFRRRGKN SRRKKGRD GRERSKRWEA QTDE I LDED TDSENSESKL I GATKGN S GRTKP T HRP T SRH SRRKN SREKKKNKTKTR S SKKRS HP KPKKSRKKQRLQRIRKKARGTRKTKLRHVKVKSKS TP IQQIETT TTMKP F FRKHKKAP TKKLFKEKKL SEDNKKKKSRAKSRNSTKVKP TYVSSMTTSDEETLTRPQG KRLMKERRARKSRTKKGNNTKSKS I LGKLVENMETESPTNWQRDG TDERWWTVEDP HF 


\section{Figure 3}

Sequences of selected echinoderm GSS.

Sequences of selected echinoderm GSS. Sequence alignment of a few echinoderm GSS showing relatively conserved A- and B- domains of the insulin core sequence and likely KR convertase cleavage sites that can be expected to be cleaved by neuroendocrine convertase as well as a few potential furin sites. Conserved cysteine residues are indicated in red, conserved amino acid residues are highlighted in black and conserved substitutions in grey. The arginine and lysine residues that form likely - or possibly in the case of Apostichopus GSS-2 - part of a convertase site are highlighted in blue. For the alignment of a larger number or echinoderm GSS sequences see Fig. S3.

Strongylocentrotus Apostichopus-1

Apostichopus-2

Acanthaster -1

Acanthaster-2

Ophiothrix-1

Ophiothrix-2

Strongylocentrotus Apostichopus-1 Apostichopus-2 Acanthaster -1 Acanthaster-2 Ophiothrix-1 Ophiothrix-2

Strongylocentrotus Apostichopus-1 Apostichopus-2 Acanthaster -1 Acanthaster-2 Ophiothrix-1 ophiothrix-2
- QQGP RNRYCGL EFARAVF TQCSMANKRS DPGAVAE SASAARY LA -------IRICGP DISRAVYQICSHG-KRGYIP P T FNS--E----- - -WSHQRI CGP DLVHALSIVCGERG---YFGGSRLVER---D-V - - - - - EKF CDNDFHLAVYQTCSTH-KRGDGEPVLSL--K--------DS S KKHCGS AFP QFVWTACSMA-KRS-NRSPRSI--D----- DSARYQP L CGREFTRAVMEICATQVKRTEPIFQRFYNAN-- - -

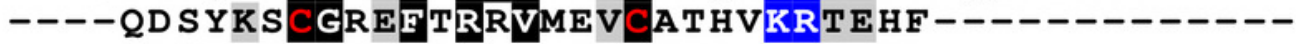

DTGYEQAEDMP LEWYDVARQGAERLRP--------SL-- TDIIF DDQLNQEFGTDL---- EEYLAETIKEYLKPNSLYDDVERELYPSI DDGLDEEITTLV-------VGAERT-------SILECLK--AWSPF D--VITGS--------------RLRG-NIRRSFGSTIE--DEAFF

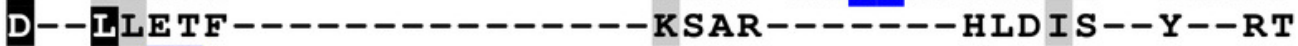

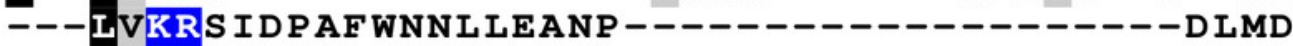
$---M V K R S I D D E F W N D L M E S G L--------------------G L--$

SRERRS I HNRGQLPMGQLCCVYGCTIVEIASVCT RG---FRRVTRTGGIARRCCSTGCSSSDIAKL --------RRRTRGIVEE SR---LVKRSEYDGIASY IR---ISKRQDYDGMADY ---- KRQSSAGVGMATH FRRCTWENIESY SKTTAYKKADNMI I HG CTP SEIAVV I IGCSTNEIIASGIC QSGCSQQEISMV -----DKR--SETGMAEHCCQNGCTDQEI SMV 


\section{Figure 4}

Sequences of selected dilp7 orthologs.

Sequences of selected dilp7 orthologs. Sequences of Drosophila dilp7 and several

ambulacrarian orthologs illustrating well conserved sequences, not only in typical insulin core of the peptides, but also in the F-domain (underlined in blue). Note that the sequence conservation of these peptides is stronger than in the IGFs or GSSs (Figs. 1,2). Conserved cysteine residues are indicated in red, conserved amino acid residues are highlighted in black and conserved substitutions in grey. Likely convertase cleavage sites have been highlighted in blue. Sequences are from Spreadsheet S1 and Veenstra 2020b, a comparison of a larger number of sequences is presented in Figs. S5 and S6.

Drosophila

Anneissia

Strongylocentrotus

Apostichopus

Acanthaster

Ophiothrix

Saccoglossus -1

Ptychodera

Schizocardium

Drosophila

Anneissia

Strongylocentrotus

Apostichopus

Acanthaster

Ophiothrix

saccoglossus-1

Ptychodera

Schizocardium

Drosophila

Anneissia

strongylocentrotus

Apostichopus

Acanthaster

Ophiothrix

Saccoglossus-1

Ptychodera

Schizocardium

- - - - L QHTEEGLEMLFRERS $Q$ SDWENVW̄HQÐTHSR-$--------------I R D Y S D R S$ HNDWARVWTVESMRQ--EKFCNCMVLPELTMEDYEDRTPEEWRESWNMDTLRT-- - - - - - - - TLQELNSRTQP SWEQLWIVENVPTVD - - - - - - AP HLPVEQWNSRSKADWVKLWNTERHVNT$------------K I T D Y S S R T K A D W Q R L W L T E S H Q K--$ LTVENEETITFSELNTMYGTRTLTDWQGKWTSETIHA-----AKDYDTVEDLILKYGTRTEDDWRNVWHTESHNK-- - - ENAYETVES LKAKYSGRTF NDWRAAWNTETHNK-

-RDKLVRQL YWAC - HENLREMVHVS VGP QLQRVGELAC TV-DAVQLHIIAC -NEALI P VWDVAC -NEDILP LWK IA - GSNIYRISEYV -RNSLYSYVIFAC - RNSIYSYVIFAC

EKDIYRLTRRNKRRT GNDEAWIKKTTTEPDGSTWLHVNYANMFLRSRR-- - RNDPRK-ISS KRS---------------- IFIPRNEAT GF LSRF I--- I NDPRKT IVVIKRSN---------- SDRDLF IPAKLAKAF LHYRHRKD-SNDVYKD HE GSRRRRF-------SDKRRRS--IF LNF SEANNF LA-KTKRTHS QND IRK-IT-KRM--------- - - -- GREF LNEWTAKNF LAGS-- - -

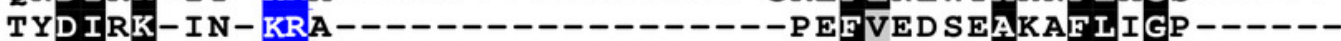
YVD I HKSP DR KRTD---------------DAFVD SAVAHDF LRGIMEKRTL MVD IYATGDK KRAE----------------P PFVEHS IAN SF LAGHRAEKRM MKD I HA S GDR KRGQ-----------------F PF LD HEVAD KF L SGS L-GKRM

SDGNTPSISNEC RTRRP SELHED SRRRRVGKDEE RVRRTTTSTE -KRRKRGLNEE -RRHKRGLNEE RRYRRTSATSE TRE RRASPTE ARF RRANP SEE
T-KAGCTWEEYAEYLDSRGCTWEEVAEIA AEAQGCRWEELGEYD--KICIWEEVGEY HEDLGCVWEEVAEYHESKG CVWEEI GEY ADDGGCVWEELAEY SNAHG CNWEELAEY SNRNGCTWEELAEY
P SNKRRNHY -

I NNRRRMHRPGSPVGR-----TIHTRAYHQSGEQP - - - - - WH-SRVYH----ン--------VMHGREKHEDGSPVRGKP GRRR RMHSRASHVDGRIDSR-----THQREVRTMDE----------SHQRDDTRRRNHQRDDIDGR----------- 


\section{Figure 5}

Sequences of selected ambulacrarian octinsulins.

Sequences of selected ambulacrarian octinsulins. Sequence alignment of a number of octinsulin sequences show that these sequences all have typical neuroendocrine convertase KR cleavage sites, suggesting these precursors are processed by enteroendocrine and/or neuroendocrine cells. Conserved cysteine residues are indicated in red, conserved amino acid residues are highlighted in black and conserved substitutions in grey. Likely convertase cleavage sites have been highlighted in blue. Sequences are from Spreadsheet S1, a comparison of a larger number of sequences is presented in Figs. S7 and S8. 
Anneissia

Strongylocentrotus Apostichopus

Acanthaster

Ophiothrix

Saccoglossus-1

Ptychodera-1

Schizocardium-1

Saccoglossus -2

Ptychodera-2

Schizocardium-2

Saccoglossus -3

Ptychodera-3

Schizocardium-3

Anneissia

Strongylocentrotus Apostichopus

Acanthaster

Ophiothrix

Saccoglossus-1

Ptychodera-1

Schizocardium-1

Saccoglossus-2

Ptychodera-2

Schizocardium-2

Saccoglossus-3

Ptychodera-3

Schizocardium-3

Anneissia

Strongylocentrotus Apostichopus

Acanthaster

Ophiothrix

Saccoglossus-1

Ptychodera-1

Schizocardium-1

Saccoglossus -2

Ptychodera-2

Schizocardium-2

Saccoglossus-3

Ptychodera-3

Schizocardium-3

Anneissia

Strongylocentrotus Apostichopus

Acanthaster

Ophiothrix

saccoglossus-1

Ptychodera-1

Schizocardium-1

Saccoglossus-2

Ptychodera-2

Schizocardium-2

Saccoglossus -3

Ptychodera-3

Schizocardium-3

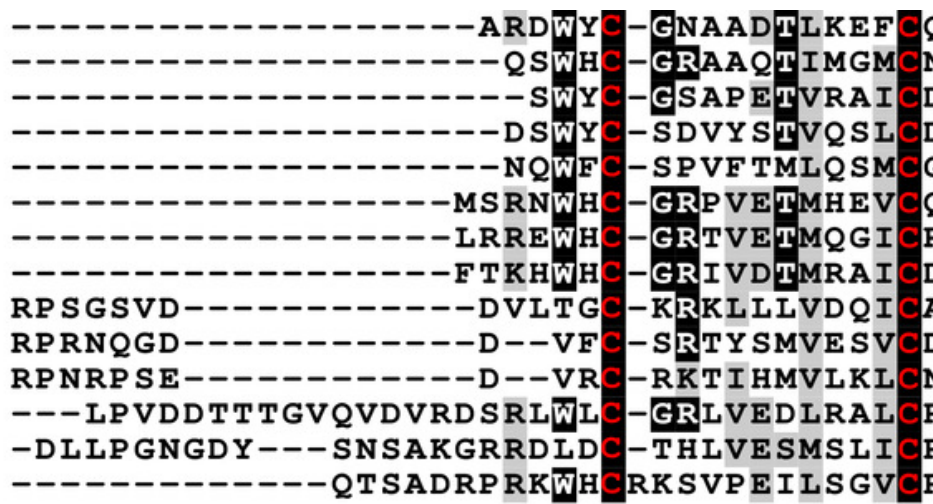

QS YASKRAHN--ALSLP NSCYASHDKRS------YAGGIHTR--AFRRS DSCYAGF DKRT------GSCYAGVDKRS--- - - OGCYAGHVRPR-----RGCYAQP SERS-----DGCYASP TARD-----AGCYAPPDIINNVNFDLT DGCYATTQDS SPKSESAM NGCLAP I ESEVENN- - T I RGCYAG-- - P------RGCYATDQGV

RGCYAEP L QP P------

S IKA-----KKDGMFLTREGASGYLEARRTRL--------FSS-LHLNHRQHETT I SKP SY-- - TPAKPELHKRNAVHFLRT TKREIESRP SMGDTAIEVAVERRSTGNR SSDIIS---LYKD PFLKKSNALNFLLPRSHTP-------S-----SLIKRGIRRS NS I TRP---I-EEPEVERKNAVDFFRRGTAR-- - - - - -G-- - - - - - - - - TRR DNSDTLSQKQSLDAFIQKEVAYSFIKRTSVG--------DT----FLRNARNTHH NTRS----VDGVQAE I SRRDANMETKGMSP D-------------V----KRAIDG T--N----EAERQAFI GKEEASSFTKSVP---------------------TIVKR V--G----SVKGLPELKKHEASTETRTRS---------------------SVQKR

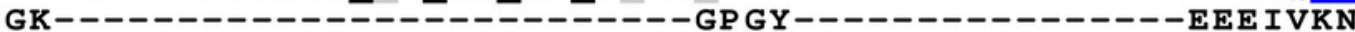

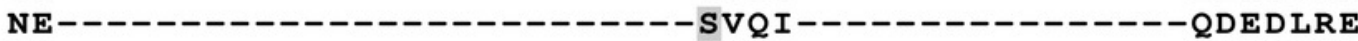

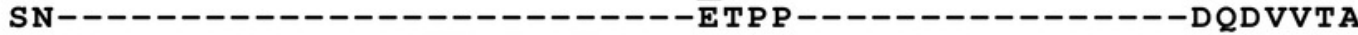
$--------------D I S K R E A S K F M Q F N A-------------------H T I R Q S R$ --------------TVNKRLASSFIPTTTTP-------------R-----NKIQR G-- - - - - - KRD I LNKQEASS LFLRS P-- - - - - - - - - - - - - - - NGGDE

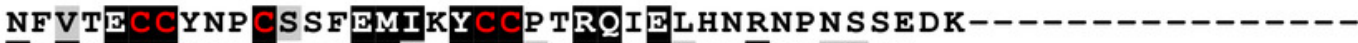
GFIHECCNKF CDP GEMVIY GFIGECCEKN CEI REMVFY GIVDECCHRQ CAVSEMMLY GLIDECCTQQCDTGEMIIY GLIEECCYSQCSI THMI TY GLIEDCCYRR CNLQKMMTY GI IEHCCNH H CSF TELL IY QIKEACCKEYCPIPKIIEF KIRDKCCNRRCTIHKMMQF KVREVCCDNYCSLDKIIEF GI IEDCCYH T CP TERKIQY GI IDECCRNRCSVERKI QY EKRQIEWAQFHNLLKA---------------AEKQREYASFFPEIFRNRIRHT-- - - - - - EQKQREYYTFVGWLKRR----------------

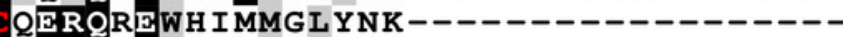
AEVQNEFQVFINILGNTDESSENDGDDGEESSSV AERQRELNNFFSLLNQKDNGST----------EERSEFFYSIGLLRMDDEDTDASLEKGNGDVEA DERQQFFHQFMSSFASTEE-------------EARRNEFHKFLALMGNTDN-------------EDLQQEFRQFMSFVSNSK--------------FEVQAQYRLFMESAI------------------LI INECCIRTCTV I EKI HY C CREKQI VI Y I I I QS APW LVDNQR
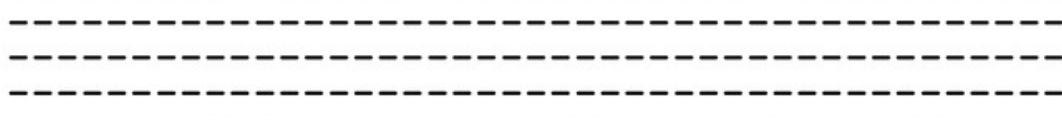

HED
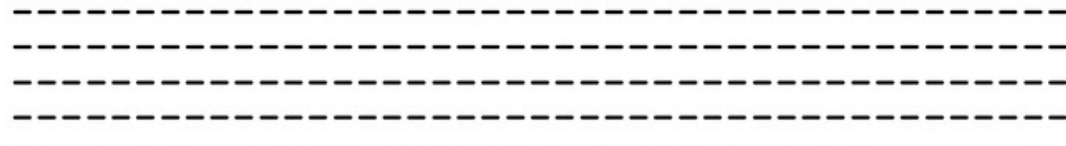


\section{Figure 6}

Sequence comparison of selected ambulacrarian multinsulins and dilp7 orthologs.

Sequence comparison of selected ambulacrarian multinsulins and dilp7 orthologs. Three different sets of sequences are compared. The top five sequences are dilp7 orthologs, the next five are multinsulins having three disulfide bridges and the last five multinsulins having four disulfide bridges. Note that although the multinsulins and the dilp7 orthologs share some sequences similarity this does not include the F-domain. Like the octinsulins these sequences all have typical neuroendocrine convertase KR cleavage sites, suggesting they are processed by enteroendocrine and/or neuroendocrine cells. Conserved cysteine residues are indicated in red, conserved amino acid residues are highlighted in black and conserved substitutions in grey. Likely convertase cleavage sites have been highlighted in blue. Sequences are from

Spreadsheet S1, a comparison of a larger number of sequences is presented in Figs. S9 and S10. 
Anneissia

Antedon

Strongylocentrotus

Apostichopus

Acanthaster

Ophiothrix

Amphiura-1

Ophioderma-1

Pisaster-2

Asterias-1

Patiria-1

Acanthaster -1

Ophioderma-5

Asterias -3

Pisaster-1

Acanthaster -3

Patiria-7

Anneissia

Antedon

Strongylocentrotus

Apostichopus

Acanthaster

Ophiothrix

Amphiura-1

Ophioderma-1

Pisaster-2

Asterias -1

Patiria-1

Acanthaster-1

Ophioderma-5

Asterias-3

Pisaster-1

Acanthaster-3

Patiria-7

Anneissia

Antedon

Strongylocentrotus

Apostichopus

Acanthaster

Ophiothrix

Amphiura-1

Ophioderma-1

Pisaster-2

Asterias-1

Patiria-1

Acanthaster-1

Ophioderma-5

Asterias -3

Pisaster -1

Acanthaster -3

Patiria-7

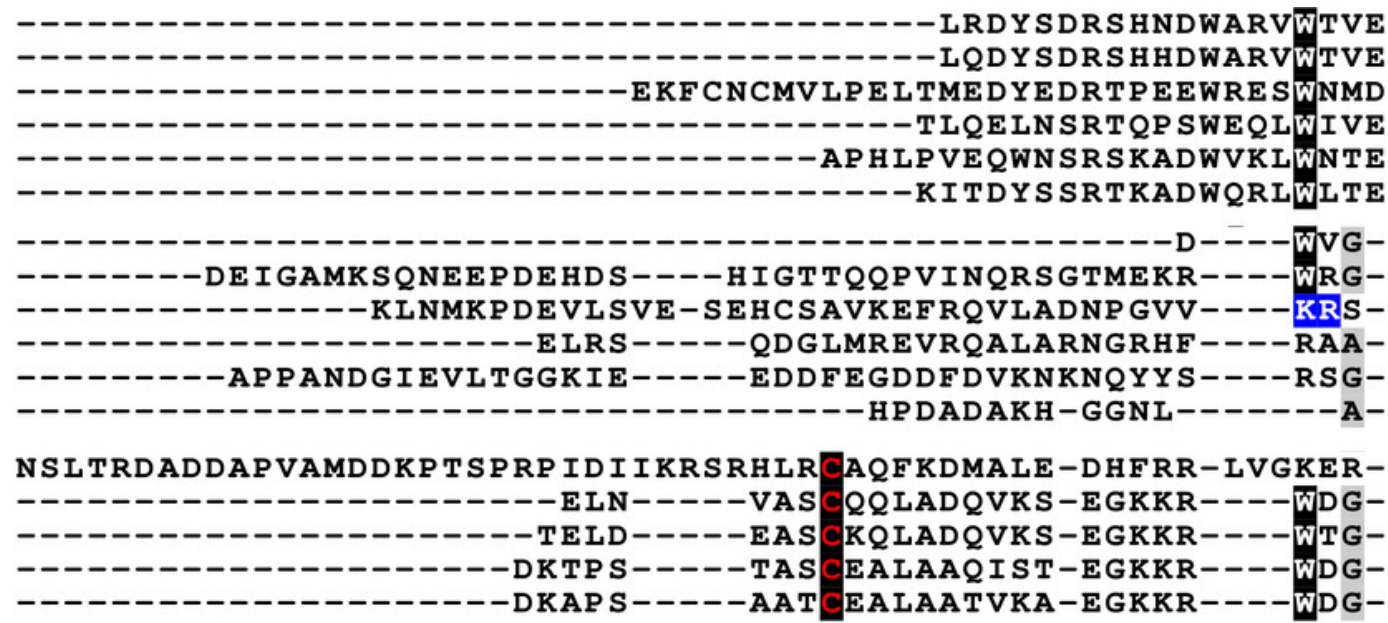

SM--RQCHENIRE--MVHVS SM--ROCHEDLRE--MVH I S TLR-TCVGP $Q L Q R--V G E L A$ NVP TVDCTVDAVQ--LH I IA RHV-NT NEALLP--VWDVA SH- - QKCNEDLLP--LWK I A

RNDPRKISS----------KR-S IFIPRNEATGFISR HNDPRKITS----------KR-S IFIPRNEATGFISR I NDPRKT IVVKR-----SNSDRDLFIPAKLAKAF LHY SNDVYKDHEGSRRRRF SDKRRRS IF LNF SEANNF LAK QNDIRKITK----------RMGREFINEWTAKNF IAG -FRT-ICDPPFTPSLYIEDFCGVTV---KR---------E------YEATDPLGFIKM -YVY-I CEPQLTR--LKNVI CNP ASVKRS----------DT AGLEFLTEHQAKRF LMQ -PRNYWCNTALSO--RKTALCGCT----HH---------TLRDDDFMEEKKDATNFLE - EDHIY CGVVLEQ--NRESV CGV--IPG------------SKRN LFVRKEAASEFIE-PRFRVCGTTTHS--WSSFVCHPSGLI-HH---------KRDNDEFISAGEANTFLMS -YRANYCGATIYE--KVRETCHA-----VR---------GVSNQEFLDSKDASTFIFG

-VF AKYCSP T P QT--VMDNYCQCDVVPRS I---------DDKRAFVDKS SAKSFLNH -PSHKF CGETLNE--KRYAY CTCGLVPRKR---------ELELSEFINRGKANGF ISA -SWHTF CGETLNE--KKYAY CTCGLVPRKR---------ELDLSEFLNRGKANGFLSA -PSHTF CGEDLNE--RRNAY CNCQVVPRKR---------ELDLSEFIPSGKANAFLSG -PAHTFCGETLTE--KANAYCHCQVVPRKR---------ELELSEFLTPVKANSFLSG

FL- - R-T-RRP S ELHEDC FL- - R-T-RRP S ELHED RHRKDS-R-RRRVGKDEE TKRTHS-RVRRTTTFSTE S------K-RRKRGLNË P------R-RHKRGLNEE

RGMVKRLNPNWRELMSEEC NKR----IWGW-GGLSEE RGI ERR-------SLSEE R--GVQ-------GLAEE EGVGKR-------GMHEE

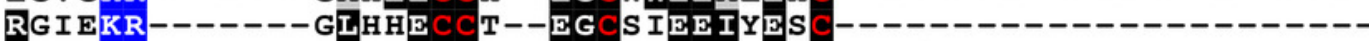

RAS - TR------ SLDEECC RNVQKR------SLSEECC RNLQKR-------SLSEE RRI TKR-------SLSEE RN I AKR-------SLTEECC
LDSRGCTWEEVAEIACINNRRRMHRP GSPVGR----LD SRG CTWEEVAEI A CI NNRRRMHRP GSPVGR----AEAQG CRWEELGEYCTLH-TRAYHQSGEQP-------D--KLCIWEEVGEY CWH--SRVYH-----------HEDLGCVWEEVAEY CVMH - GREKHEDGSPVRGKPGRRR HES KGCVWEE I GEY CRMH-SRAS HVDGRIDSR------

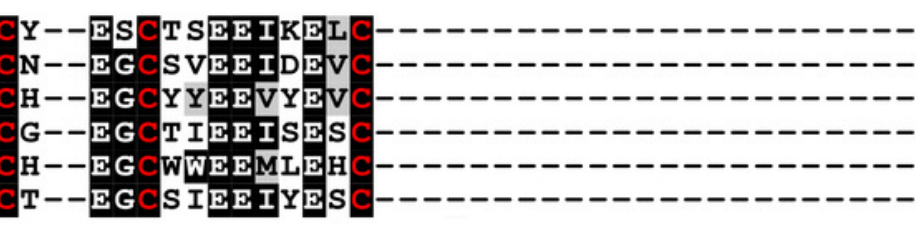

N- EGCNLEEIVDL SKTMCS S S - - - - - - - - - - - - -

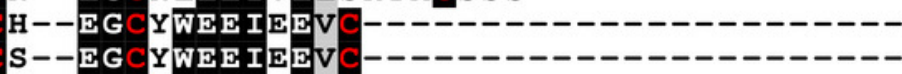
H-DGCYWEEIEVVC-------------------H-DGCYWEEIE FVC--------------------- 


\section{Figure 7}

Position of introns in ambulacrarian irp genes

Schematic representation of the location of the cysteine residues, indicated as purple rectangles, and introns, represented by green T's, in the coding sequences of the various types of ambulacrarian insulin-like genes. Numbers indicate the phase of each intron. All genes share the typical phase 1 intron present in insulin-like genes, whereas dilp7 and multinsulin genes also share a phase 2 intron. Signal peptides indicated as interrupted bars.

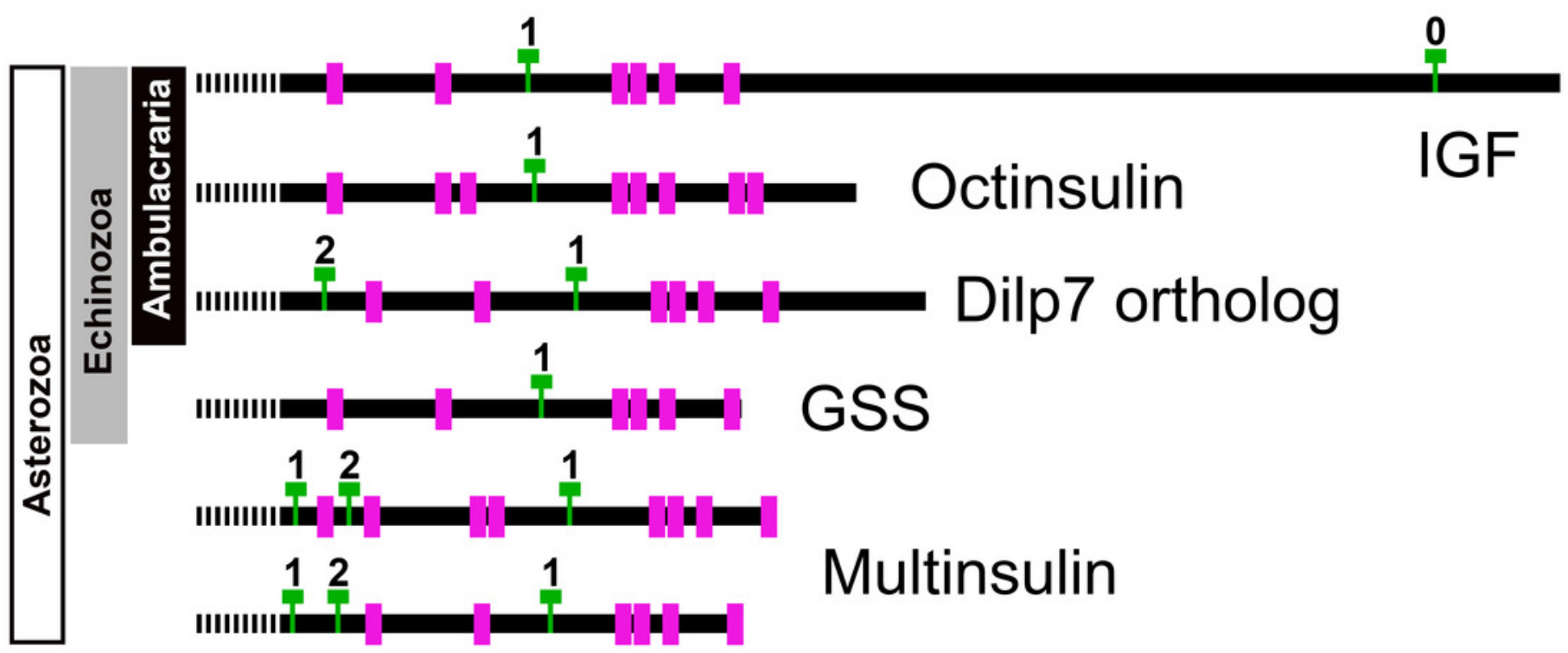




\section{Figure 8}

Synteny of ambulacrarian irp genes.

Schematic representation of the relative localization of different irp genes in several arthropod and ambulacrarian genomes. Arrow heads indicate transcription direction of the various genes, the numbers below the line indicate the number of nucleotides between the coding regions of adjacent genes in kilo base pairs. Note that the relative organization of the two insects - the cockroach Blattella germanica and the stick insect Timema crisitinae - is the same as in the hemichordate Saccoglossus kovalewskii and remarkably similar to that of the sea urchin Strongylocentrotus purpuratus and the sea cucumber Holothuria scabra. In the spider Pardosa pseudoannulata and the sea cucumber Apostichopus japonicus some of the genes are also next to one another. However, in the sea stars Acanthaster planci and Pisaster ochraceus synteny has been lost. Arthropod data from Veenstra, 2020b. 
Pardosa

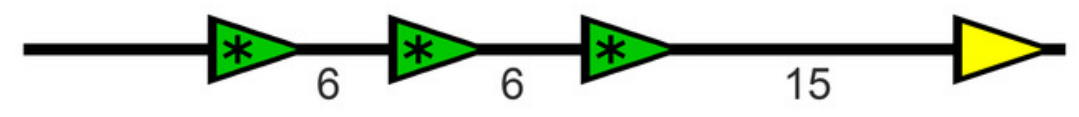

Blattella

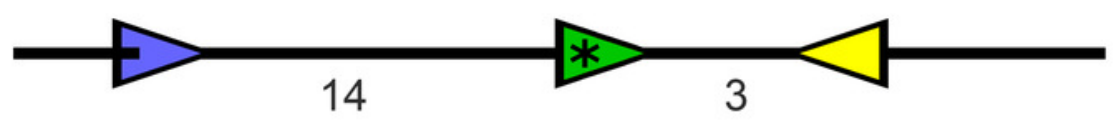

Timema

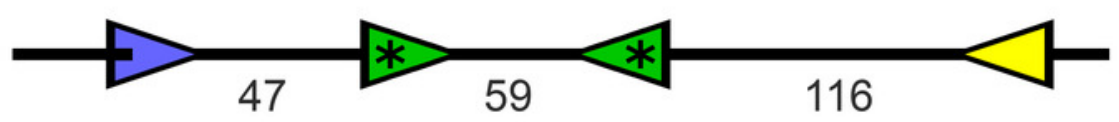

Saccoglossus

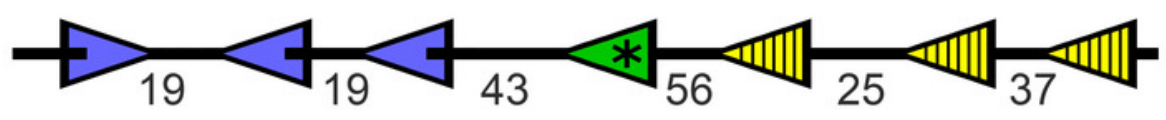

Strongylocentrotus

Holothuria

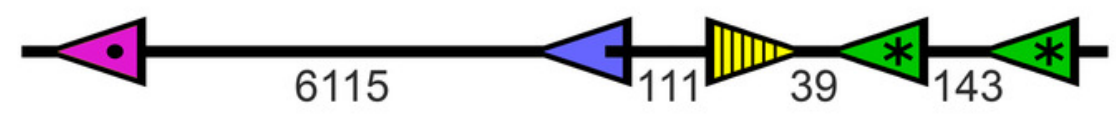

Apostichopus

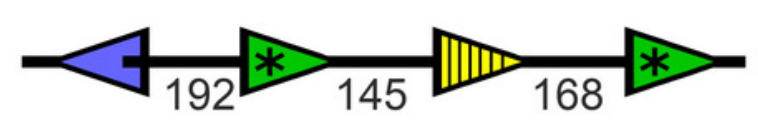

Pisaster
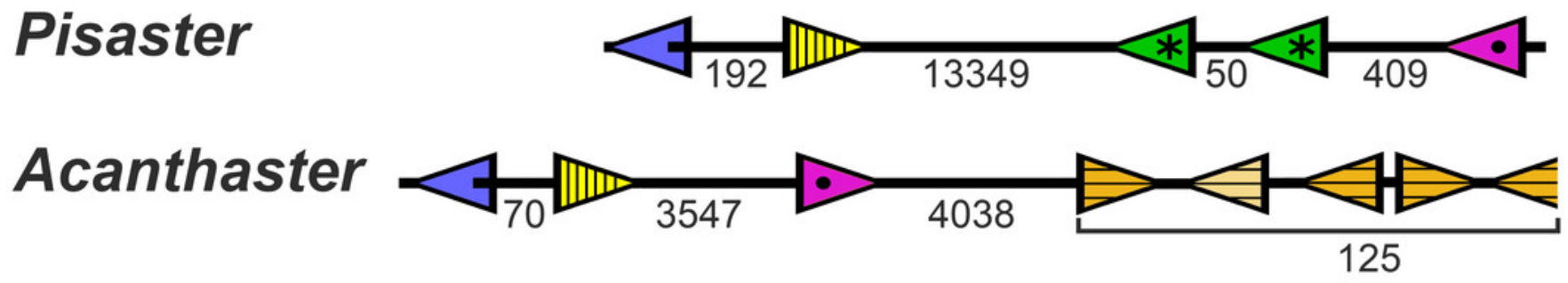

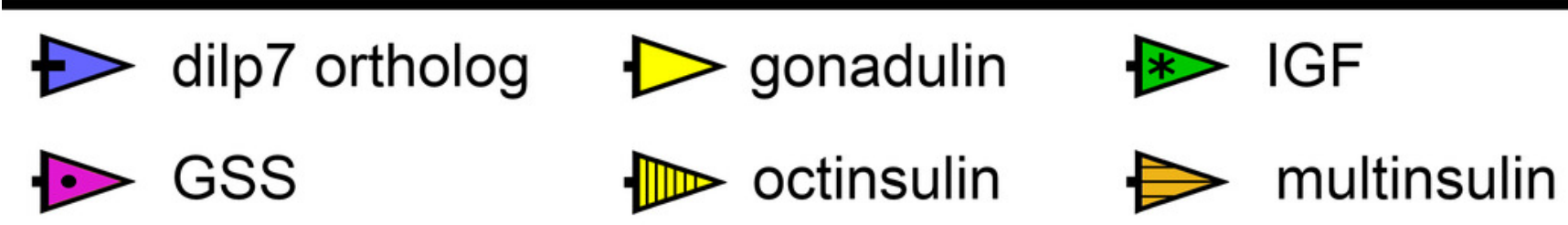




\section{Figure 9}

Radial sequence similarity tree of ambulacrarian irps.

The five different types of irps are clearly separated from one another. Note that the GSSs are similar to IGFs and seem to be related to them, while the multinsulins are most similar to the dilp7 orthologs. Echinoderm branches are in black, hemichordate branches in red. More extensive sequence comparisons and sequence trees are the supplementary data (Figs. S1S10). All sequences are from Spreadsheet S1. 


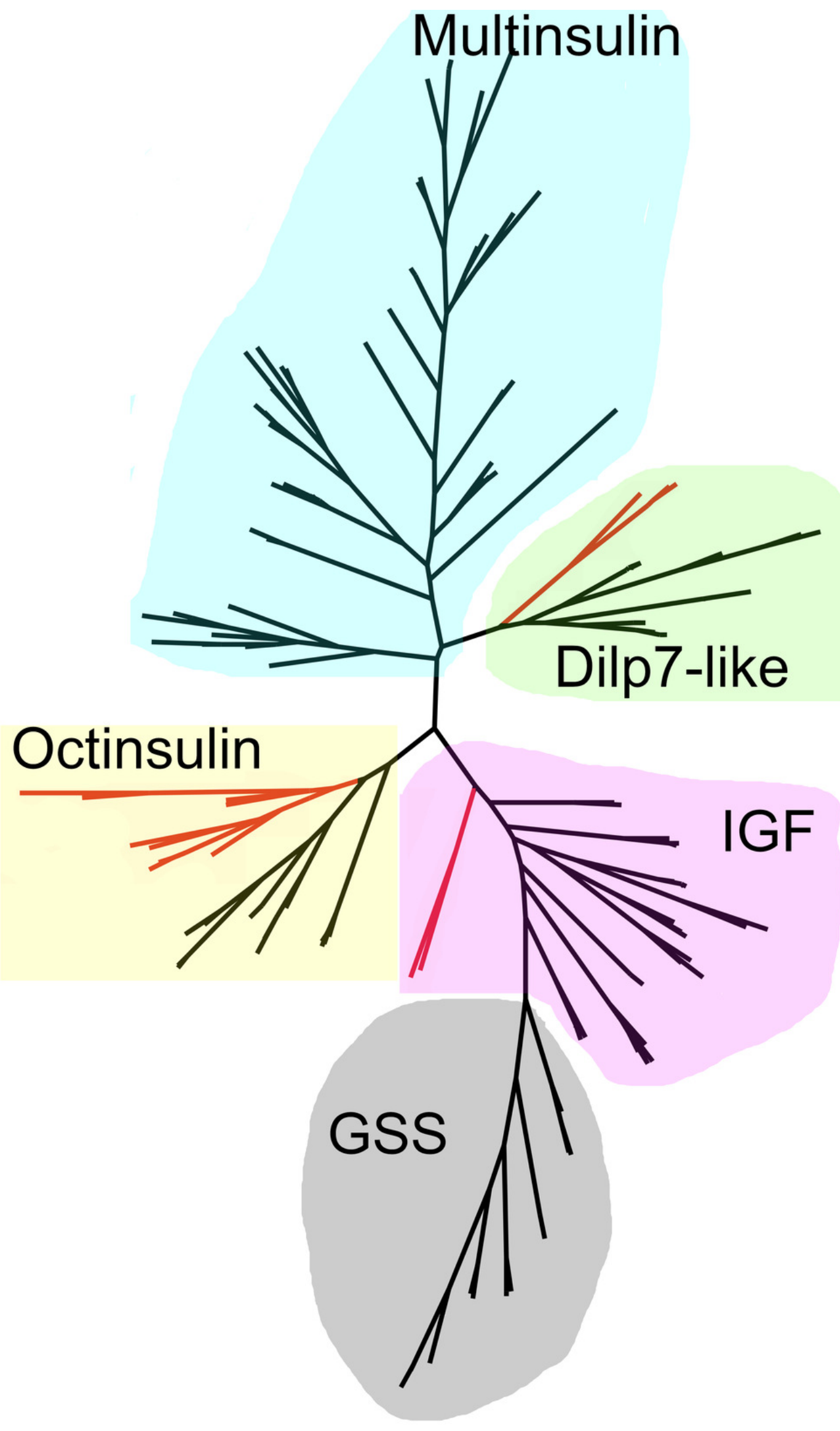




\section{Figure 10}

Phylogenetic tree of LGRs.

Phylogenetic tree constructed from the transmembrane regions of ambulacrarian LGRs that are putative receptors for irps. A few human and insect sequences have been added for comparison. The insert at the top shows the same data to which the glycoprotein LGRs have been added and where characteristic ligands for each branch have been identified. Numbers in blue indicate the apparent probabilities as determined by Fasttree. For details of the glycoprotein LGRs see Fig. S11. 


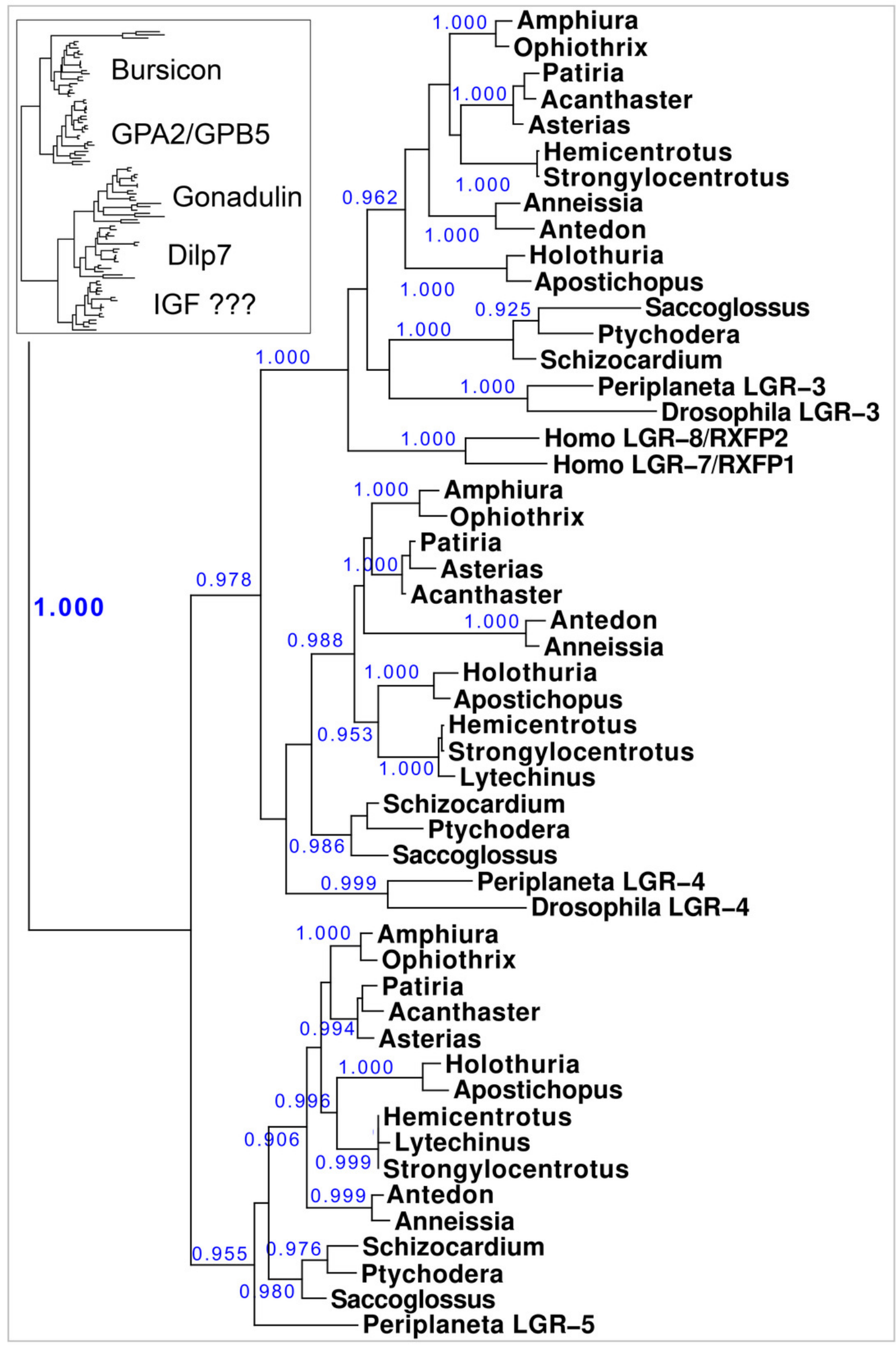




\section{Figure 11}

Ectodomains of ambulacrarian LGRs.

Ectodomains of ambulacrarian LGRs. Schematic representation of the various domains of the putative receptors for ambulacrarian insulin-related peptides. Each green circle symbolizes an LDLa repeat and each purple rectangle an LRR repeat, while the yellow oval indicates the seven transmembrane regions. The top representation corresponds to the gonadulin and dilp7 receptors (Figs. S11,S12). Note though, that the latter are somewhat variable, notably in the sea stars of two species of the Patiria genus and Acanthaster planci those receptors have two LDLa repeats (for details see Fig. S12). The bottom representation corresponds to the GRL101 receptors (Fig. S13).
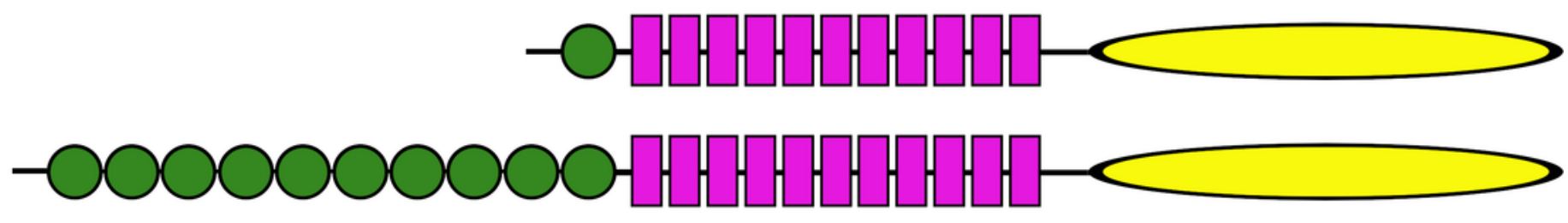


\section{Figure 12}

How echinoderm irps may have evolved.

A represent an early metazoan in which an arch irp is a ligand for both an LGR and an RTK. B represents an early protostome or deuterostome that has three irps, an IGF and a dilp7 ortholog as well as gonadulin/octinsulin ortholog that evolved from local gene duplication from the arch irp. All three of these ligands each each their own LGR and at least two of them, IGF and the dilp7 ortholog, can also activate the RTK. C represents the Asterozoa where the dilp7 gene got duplicated and yielded several multinsulin genes which are represented here as one. The Asterozoa also have one or two GSS's that evolved earlier during echinoderm evolution. Both multinsulins and GSS's act exclusively through the RTK. Closed arrows indicate gene duplication events and interrupted arrows show ligand-receptor interactions. The question mark conveys uncertaintity with regard to whether or not the gonadulin/octinsulin peptides are able to activate the RTK. 

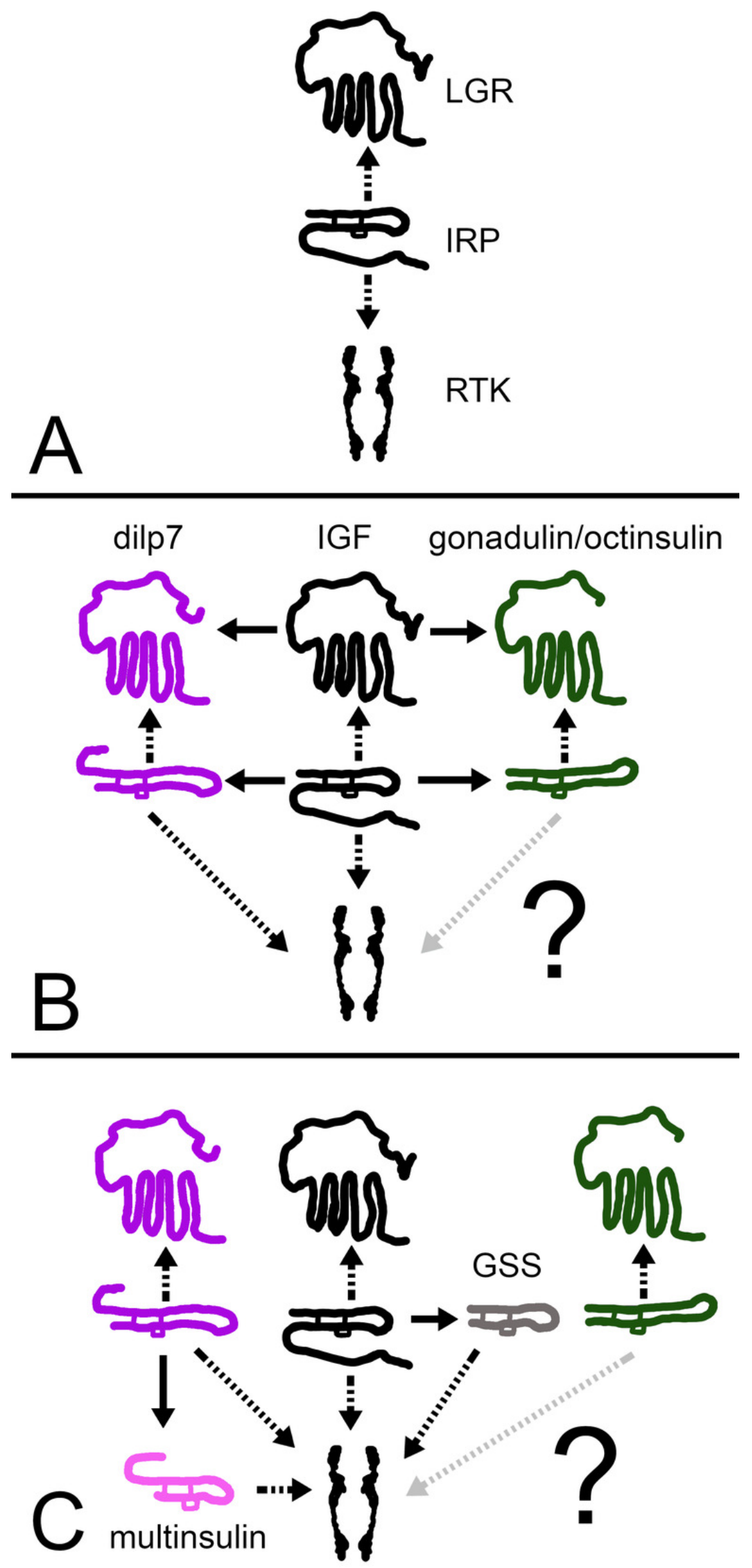

PeerJ reviewing PDF | (2021:04:60199:2:0:REVIEW 22 Jun 2021) 